OPEN ACCESS

Edited by:

Paula Casati,

Consejo Nacional de Investigaciones

Cientificas y Técnicas (CONICET),

Argentina

Reviewed by:

Anabella Fernanda Lodeyro,

CONICET Instituto de Biología

Molecular y Celular de Rosario (IBR),

Argentina

Martin Hagemann,

University of Rostock, Germany

*Correspondence:

II-Sup Kim

92kis@hanmail.net

James W. Golden

jwgolden@ucsd.edu

Ho-Sung Yoon

hsy@knu.ac.kr

${ }^{\dagger}$ These authors have contributed equally to this work

Specialty section:

This article was submitted to

Plant Abiotic Stress,

a section of the journal

Frontiers in Plant Science

Received: 18 September 2018 Accepted: 28 November 2018 Published: 11 December 2018

Citation:

Kim Y-S, Kim J-J, Park S-I,

Diamond S, Boyd JS, Taton A, Kim I-S, Golden JW and Yoon H-S

(2018) Expression of OsTPX Gene Improves Cellular Redox Homeostasis and Photosynthesis Efficiency

in Synechococcus elongatus PCC 7942. Front. Plant Sci. 9:1848. doi: 10.3389/fpls.2018.01848

\section{Expression of OsTPX Gene Improves Cellular Redox Homeostasis and Photosynthesis Efficiency in Synechococcus elongatus PCC 7942}

\author{
Young-Saeng Kim ${ }^{1 \dagger}$, Jin-Ju Kim ${ }^{2,3+}$, Seong-Im Park²,3, Spencer Diamond ${ }^{4}$, \\ Joseph S. Boyd ${ }^{4}$, Arnaud Taton ${ }^{4}$, II-Sup Kim ${ }^{5 *}$, James W. Golden ${ }^{4 *}$ and \\ Ho-Sung Yoon ${ }^{2,3,5 *}$
}

\begin{abstract}
${ }^{1}$ Research Institute of Ulleung-do and Dok-do, Kyungpook National University, Daegu, South Korea, ${ }^{2}$ Department of Biology, College of Natural Sciences, Kyungpook National University, Daegu, South Korea, ${ }^{3}$ School of Life Sciences, BK21 Plus KNU Creative BioResearch Group, Kyungpook National University, Daegu, South Korea, ${ }^{4}$ Division of Biological Sciences, San Diego, La Jolla, CA, United States, ${ }^{5}$ Advanced Bio-Resource Research Center, Kyungpook National University, Daegu, South Korea
\end{abstract}

Cyanobacterial 2-Cys peroxiredoxin (thioredoxin peroxidase, TPX) comprises a family of thiol antioxidant enzymes critically involved in cell survival under oxidative stress. In our previous study, a putative TPX was identified using a proteomics analysis of rice (Oryza sativa L. japonica, OsTPX) seedlings exposed to oxidative stress. This OsTPX gene is structurally similar to the Synechococcus elongatus TPX gene in the highly conserved redox-active disulfide bridge (Cys114, Cys236) and other highly conserved regions. In the present study, the OSTPX gene was cloned into rice plants and S. elongatus PCC 7942 strain to study hydrogen peroxide $\left(\mathrm{H}_{2} \mathrm{O}_{2}\right)$ stress responses. The OsTPX gene expression was confirmed using semi-quantitative RT-PCR and western blot analysis. The OSTPX gene expression increased growth under oxidative stress by decreasing reactive oxygen species and malondialdehyde level. Additionally, the OsTPX gene expression in S. elongatus PCC 7942 (OT) strain exhibited a reduced loss of chlorophyll and enhanced photosynthesis efficiency under $\mathrm{H}_{2} \mathrm{O}_{2}$ stress, thereby increasing biomass yields twofold compared with that of the control wild type (WT) strain. Furthermore, redox balance, ion homeostasis, molecular chaperone, and photosynthetic systems showed upregulation of some genes in the OT strain than in the WT strain by RNA-Seq analysis. Thus, OsTPX gene expression enhances oxidative stress tolerance by increasing cell defense regulatory networks through the cellular redox homeostasis in the rice plants and S. elongatus PCC 7942.

Keywords: cyanobacteria, defense system, hydrogen peroxide, redox balance, thioredoxin peroxidase

\section{INTRODUCTION}

The metabolism of most aerobic organisms inevitably produce reactive oxygen species (ROS) that are capable of irreversibly damaging vital cell components. In response to rising levels of ROS, cells employ additional strategies to limit damage (Day et al., 2012). For instance, signaling pathways are activated to increase the levels of detoxification and repair enzymes. Paradoxically, hydrogen 
peroxide $\left(\mathrm{H}_{2} \mathrm{O}_{2}\right)$, one of the most representative ROS, is associated with this cellular signaling pathway. $\mathrm{H}_{2} \mathrm{O}_{2}$ concentrations increase in response to various abiotic and biotic stresses and take part in the reactive oxygen regulatory network (Mittler et al., 2004). Therefore, the intracellular $\mathrm{H}_{2} \mathrm{O}_{2}$ concentration needs to be carefully regulated to balance its toxic and signaling activities (Puerto et al., 2015).

To modulate peroxide balance, cells express this set of $\mathrm{H}_{2} \mathrm{O}_{2}$ decomposing enzymes; catalase peroxidase, ascorbate peroxidase, glutathione peroxidase, and 2-Cys peroxiredoxin (thioredoxin peroxidase, TPX). TPX, a thiol-specific peroxidase, catalyzes the reduction of $\mathrm{H}_{2} \mathrm{O}_{2}$ and plays a role in protecting cells against oxidative stress by detoxifying peroxides, and by acting as a sensor for hydrogen peroxide-mediated signaling events. Furthermore, TPX belongs to a conserved family of antioxidant genes, the peroxiredoxin, which use thiol groups as a source of reducing equivalents to scavenge oxidant species (Chae et al., 1994). The catalytic breakdown of $\mathrm{H}_{2} \mathrm{O}_{2}$ by TPX gene involves the oxidation of the peroxide-reactive peroxidatic cysteine (Cys), located in the N-terminal of proteins (Dietz et al., 2006), followed by the formation of a disulfide with the resolving Cys (Day et al., 2012). Subsequently, thioredoxin (TRX) reduces the oxidized TPX back to the monomeric form. These reactions are critical in protecting cells from ROS-induced stress and minimizing their subsequent degradation (Dietz, 2007).

A number of studies have addressed the function of TPX gene in peroxide detoxification and redox regulation under stress conditions in various species. For instance, TPX gene protects cells against $\mathrm{H}_{2} \mathrm{O}_{2}$ induced damage in humans (Berggren et al., 2001). TPX not being expressed resulted in weakened phenotypes that were very sensitive to oxidative stress within Arabidopsis thaliana (Finkemeier et al., 2005) and Synechocystis sp. PCC 6803 (Klughammer et al., 1998). Additionally, overexpression of heterologous TPX in transgenic plants conferred heat and methyl viologen tolerance in tall fescue (Kim et al., 2010), and promoted higher resistance against oxidative stress by enhancing antioxidant activity in transgenic tobacco (Lee et al., 2000). Moreover, our previous study demonstrated that expression of Oryza sativa (O. Sativa) TPX (OsTPX) increased oxidative stress tolerance and fermentation capacity by improving cellular redox homeostasis in Saccharomyces cerevisiae (Kim et al., 2013). The TPX sequences of the above-mentioned species have strictly conserved residues that function as redox active sites, which are functionally similar to conserved residues. These TPX sequences possess enhanced abilities to catalyze antioxidants and antioxidant-related enzymes under ROS-induced oxidative stress. Because the function of the redox active site is functionally similar to these conserved residues, heterologous TPX could act in a role similar to the cyanobacteria TPX. However, interaction with heterologous TPX has not been extensively studied in cyanobacteria under ROS-induced oxidative stress.

In the previous study, the heterologous expression of the OsTPX gene in the genetically modified Synechococcus elongatus (S. elongatus) strain PCC 7942 was found to improve tolerance to stress, photosynthetic efficiency, and cell viability under ROSinduced oxidative stress. Therefore, in the present study we profiled gene expression to identify the mechanisms preventing
$\mathrm{H}_{2} \mathrm{O}_{2}$ stress. Our results demonstrated improved cellular redox homeostasis by enhancing oxidative stress tolerance and photosynthesis efficiency upon the introduction of the heterologous OsTPX gene, which affected the cell defense regulatory network through redox balance in S. elongatus PCC 7942.

\section{MATERIALS AND METHODS}

\section{Plant Growth Conditions}

The TPX gene from O. sativa L. japonica was transfected into Ilmi cultivars of rice plants. Genotypes and phenotypes were screened by germinating transgenic rice plants and non-transgenic wild type (WT) rice seeds at $28^{\circ} \mathrm{C}$ for 3 days. The subsequently germinated seedlings were transplanted and grown for 4 weeks in a greenhouse $\left(28-32^{\circ} \mathrm{C}, 16 \mathrm{~h}\right.$ light $/ 8 \mathrm{~h}$ dark cycle). The seedlings were then placed in a $50 \mathrm{mM} \mathrm{H} \mathrm{H}_{2} \mathrm{O}_{2}$ solution for 1 week each in three independent biological replicates and were used in the following experiments.

\section{Amino Acid Sequence Alignment}

The BLAST software ${ }^{1}$ was used to align OsTPX with known TPX sequences using the National Center for Biotechnology Information (NCBI) database. The gene sequences were as follows: OsTPX, accession no. AK068919.1; SeTPX, accession no. AF492495.1; ScTPX, accession no. NC_001145.3; AnTPX, accession no. BA000019.2; MaTPX, accession no. AP009552.1; TeTPX, accession no. BA000039.2; AmTPX, accession no. CP000828.1; and AtTPX, accession no. AF324996.2, which has been shown to be a soluble monomeric enzyme that contains one molecule of 2-Cys per enzyme molecule, enabling the assessment of different amino acid positions present in protein active sites.

\section{Conjugation and Construction of Recombinant Plasmid OsTPX}

The chloroplastic 2-Cys peroxiredoxin BAS1 (accession no. AK068919.1; OsTPX) coding region was amplified from cDNA using PCR with ExTaq polymerase (Takara Bio Inc., Shiga, Japan). The PCR reaction conditions were as follows; initial denaturation at $94^{\circ} \mathrm{C}$ for $3 \mathrm{~min}$, followed by 30 cycles of $94^{\circ} \mathrm{C}$ for $30 \mathrm{~s}, 54^{\circ} \mathrm{C}$ for $30 \mathrm{~s}, 72^{\circ} \mathrm{C}$ for $1 \mathrm{~min}$, and a final extension for $7 \mathrm{~min}$ at $72^{\circ} \mathrm{C}$. The OsTPX gene was PCR cloned using sense and antisense primers, respectively (Supplementary Table S2). The PCR product was purified using a gel extraction kit (Nucleogen, Siheung, South Korea) and then inserted into the rice constitutive vector $p G A 2897$ and cyanobacterial expression vector $p C V 0069$ (Supplementary Table S1) (Kim et al., 2017). Competent Escherichia coli DH5 $\alpha$ cells that had been transformed with the binary vectors were selected using hygromycin and nourseothricin (Nat, $50 \mu \mathrm{g} \mathrm{mL}^{-1}$ ). Expression clones were confirmed by sequencing before using them to transform $O$. sativa and $S$. elongatus. The binary vector of rice was introduced into Agrobacterium strain LBA4404 by electroporation and subsequent plant transformation in O. sativa

${ }^{1}$ http://clustalw.ddbj.nig.ac.jp/ 
(Hiei et al., 1994). The cloned cyanobacterial plasmid was sequenced using the NS2 primers (Supplementary Table S2), which were complementary to the neutral site II (NS2) region, to confirm proper gene ligation and direction. Finally, the resulting plasmid was assembled using the GeneArt Seamless Cloning and Assembly kit (Life Technologies, United States). The plasmids from cloned DNA were conjugated to S. elongatus using published protocols (Golden et al., 1987).

\section{Semi RT-PCR}

The cDNA was reverse transcribed from total RNA using the SuperScript III kit (Life Technologies, United States). Semi-RTPCR was performed as follows; one cycle at $95^{\circ} \mathrm{C}$ for $3 \mathrm{~min}$, followed by $26-28$ cycles at $94^{\circ} \mathrm{C}$ for $30 \mathrm{~s}, 54^{\circ} \mathrm{C}$ for $30 \mathrm{~s}, 72^{\circ} \mathrm{C}$ for $40 \mathrm{~s}$, and then a final extension at $72^{\circ} \mathrm{C}$ for $5 \mathrm{~min}$. The semi-RT-PCR amplicons were resolved using a $0.7 \%$ agarose gel in $0.5 \times$ Tris/borate/EDTA buffer. The primer sets are described in Supplementary Table S2. The tubulin and rpoA gene primer sets were used for the housekeeping control and were amplified.

\section{Western Blot Analysis}

For the western blot analysis of the crude extracts, total cyanobacterial protein $\left(\mathrm{OD}_{730}=0.30\right)$ was obtained using a suspension of a cold extraction buffer containing; $150 \mathrm{mM} \mathrm{NaCl}$, $50 \mathrm{mM}$ Tris- $\mathrm{HCl}, \mathrm{pH} 7.3,1 \mathrm{mM}$ EDTA, $2 \% \beta$-mercaptoethanol, $1 \mathrm{mM}$ dithiothreitol, $1 \mathrm{mM}$ phenylmethylsulfonyl fluoride, which were mixed with an equal volume of phenol saturated with Tris- $\mathrm{HCl}$ at $\mathrm{pH}$ 7.3. The rice protein was extracted from tissues using published protocols (Kim et al., 2013). Briefly, crude protein extracts were prepared using glass beads. Cells grown for 7 days were exposed to $2.5 \mathrm{mM} \mathrm{H}_{2} \mathrm{O}_{2}$ for $2 \mathrm{~h}$ to induce cellular oxidative stress, followed by vigorous vortexing of 10 times for $1 \mathrm{~min}$ on ice. The protein extracts were then cleared by centrifugation at $12,000 \mathrm{rpm}$ for $20 \mathrm{~min}$ at $4^{\circ} \mathrm{C}$. Finally, the protein concentrations were determined using a Pierce bicinchoninic acid protein assay kit (Thermo Scientific, Waltham, MA, United States) (Komatsu et al., 2009; Peng et al., 2011). Protein extracts $(20 \mu \mathrm{g})$ were separated using 10\% SDSPAGE at $100 \mathrm{~V}$ and transferred onto polyvinylidene fluoride membranes (Bio-Rad, Hercules, CA, United States). These were then incubated in a blocking buffer consisting of $5 \%$ nonfat skim milk, and $0.02 \%$ sodium azide in Tris-buffered saline plus Tween (TBST, 10\% Tween-20, 20 mM Tris- $\mathrm{HCl}, \mathrm{pH}$ 7.6; and $150 \mathrm{mM} \mathrm{NaCl}$ ), for $1.5 \mathrm{~h}$ at $24^{\circ} \mathrm{C}$. The blots were then incubated overnight at $4^{\circ} \mathrm{C}$ with anti-TPX (Ab Frontier, Seoul, South Korea) antibodies appropriately diluted with a blocking buffer. The blots were then washed three times for $30 \mathrm{~min}$ with TBST, after which they were incubated with conjugated antirabbit secondary antibodies (Santa Cruz Biotechnology, Santa Cruz, CA, United States) diluted with a blocking buffer (without $0.02 \%$ sodium azide) for $4 \mathrm{~h}$ at $25-30^{\circ} \mathrm{C}$. After washing with TBST, proteins binding to antibodies on the blots were visualized using the SuperSignal West Femto substrate kit (Pierce, Rockford, IL, United States) and imaged using a MultiImage II Light Cabinet (DE-500) (Alpha Innotech Corporation, San Leandro, CA, United States).

\section{Cyanobacterial Growth and Stress Treatment Condition}

After culturing for 2 days at $30^{\circ} \mathrm{C}$ with shaking; aliquots of each sample were collected and the absorbance was measured at $730 \mathrm{~nm}$. When the $\mathrm{OD}_{730}$ value was 0.3 , the aliquots were diluted, and new measurements were taken. Cyanobacteria cells were cultured in BG11 medium containing $2.5 \mathrm{mM} \mathrm{H}_{2} \mathrm{O}_{2}$ for 7 days. To evaluate the response to oxidative stress, cells were allowed to reach the growth phase $\left(\mathrm{OD}_{730}=0.30-0.35\right)$, exposed to $2.5 \mathrm{mM}$ $\mathrm{H}_{2} \mathrm{O}_{2}$ for 2 days at $30^{\circ} \mathrm{C}$ with shaking. For plate cell-spotting assay, the OT, NS, and WT strains $\left(\mathrm{OD}_{730}=0.35\right)$ were exposed to $2.5 \mathrm{mM} \mathrm{H}_{2} \mathrm{O}_{2}$ for 2 days and were serially diluted (10-fold) with distilled water. The diluted samples were then spotted on agarsolidified BG11 medium, followed by the cell suspensions being incubated for 2 days at $30^{\circ} \mathrm{C}$ before they were photographed or counted.

\section{Measurement of Ion Leakage}

Ion leakage was analyzed using leaf disks, as described by Lee et al. (2007), with slight modifications. Ten rice leaf disks from five different plants were immediately floated on a solution containing $10 \mu \mathrm{M}$ methyl viologen (MV) in deionized $\mathrm{H}_{2} \mathrm{O}$. The leaf disks were incubated in dark for $12 \mathrm{~h}$ at $25^{\circ} \mathrm{C}$ to allow the $\mathrm{MV}$ to diffuse into the leaves. After pre-incubation, the leaf disks were placed under continuous white light until use. The extent of cellular membrane damage was quantified by ion leakage from 0 to $72 \mathrm{~h}$ using a conductivity meter (Isteck). At the end of the specified period, the samples were autoclaved for $15 \mathrm{~min}$ at $121^{\circ} \mathrm{C}$. Next, the solution conductivity was measured again, and this value was considered $100 \%$ ion leakage in subsequent calculations of the relative ion leakage at different time periods. The visible damage caused by MV application was repeated three times.

\section{Measurement of MDA and ROS Level}

The level of lipid peroxidation was determined in cells exposed to $\mathrm{H}_{2} \mathrm{O}_{2}$ for 2 days. The level of oxidative damage to lipids was determined by measuring the content of malondialdehyde (MDA) prepared in 10\% trichloroacetic acid containing $0.65 \%$ 2-thiobarbituric acid (TBA) and heated at $95^{\circ} \mathrm{C}$ for $25 \mathrm{~min}$. Finally, the MDA concentration of the resulting supernatant was measured at $532 \mathrm{~nm}, 600 \mathrm{~nm}$, and estimated using an absorbance coefficient of $1.56 \times 105$, as described by Hodges et al. (1999). The level of lipid peroxidation was determined in rice plants by measuring MDA through a TBA assay (Kim et al., 2014). The intracellular $\mathrm{H}_{2} \mathrm{O}_{2}$ levels of cells exposed to $\mathrm{H}_{2} \mathrm{O}_{2}$ for 2 days were determined using the FOX reagent (100 $\mu \mathrm{M}$ xylenol orange, 250 $\mu \mathrm{M}$ ammonium ferrous sulfate, $100 \mathrm{mM}$ sorbitol, and $25 \mathrm{mM}$ sulfuric acid) by ferrous ion oxidation in the presence of a ferric ion indicator, xylenol orange (Kim et al., 2011). To measure the cellular ROS levels in vivo, strains harvested from the $100 \mathrm{~mL}$ culture $\left(\mathrm{OD}_{730}=0.30-0.35\right)$ were exposed to $2.5 \mathrm{mM} \mathrm{H}_{2} \mathrm{O}_{2}$ for 2 days and incubated for $20 \mathrm{~min}$ at $30^{\circ} \mathrm{C}$ with $10 \mu \mathrm{M}$ DCFHDA (Invitrogen) in the dark. Next, the cells were collected and analyzed using a fluorospectro-photometer (Cal Zeiss, LSM700) at an excitation of $488 \mathrm{~nm}$ and an emission wave length of 
$535 \mathrm{~nm}$. Images were also captured by LSCM at $488 \mathrm{~nm}$ for excitation (Huang et al., 2012). The $\mathrm{H}_{2} \mathrm{O}_{2}$ levels in the rice plants were measured using the method described by Kim et al. (2014), with minor modifications.

\section{Measurement of Chlorophyll Content and Biomass Yield}

For the chlorophyll content assays, strains were harvested from $100 \mathrm{~mL}$ cultures $\left(\mathrm{OD}_{730}=0.30-0.35\right)$ after 2 days of $2.5 \mathrm{mM}$ $\mathrm{H}_{2} \mathrm{O}_{2}$ treatment. The cultivated whole cells were harvested from $5 \mathrm{~mL}$ culture $\left(\mathrm{OD}_{730}=0.3-0.35\right)$, with whole pellets being resuspended in $90 \%$ methanol, and measured using the method of Halimatul et al. (2014) with some modifications. The absorption spectra of the cells were determined by harvesting $300 \mu \mathrm{L}$ of the extracted chlorophyll in the presence and absence $2.5 \mathrm{mM}$ $\mathrm{H}_{2} \mathrm{O}_{2}$. Next, the chlorophyll assays were performed by scanning from 260 to $800 \mathrm{~nm}$ using a spectrophotometer (Infinite M200 Pro microplate reader, Tecan). All assays had three biological replicates. For chlorophyll estimation within rice plants, the leaves were sampled from plants grown for 4 weeks in $50 \mathrm{mM}$ $\mathrm{H}_{2} \mathrm{O}_{2}$ solution. Total chlorophyll contents were calculated using extraction coefficients and equations reported previously (Park et al., 2017), and expressed as values (\%) relative to that of the WT rice plants $\left(\mathrm{mg} \mathrm{g}^{-1} \mathrm{FW}\right)$. The biomass yield was determined gravimetrically according to the method of Rai et al. (2014). A known volume of algal culture was centrifuged at 5,000 rpm for $10 \mathrm{~min}$ and the harvested biomass was vacuum-dried at $60^{\circ} \mathrm{C}$ until a constant weight was reached.

\section{Chlorophyll Fluorescence Image and Quantum Yield Analysis}

Images were acquired using a FluorCAM 800MF, open version (PSI, Brno, Czech Republic) with a computer-operated control unit (SN-FC800-082, PSI) and a CCD camera (CCD381, PSI) with an F1.2 (2.8-6 mm) objective (Eneo, Japan). The data were analyzed according to Leal et al. (2015). An Aquapen-C APC 100 fluorometer (Photon Systems Instrument, Czechia) was used to measure chlorophyll fluorescence. The OJIP transient measurement induces fluorescence with blue plus red light, and detects fluorescence between 260 and $800 \mathrm{~nm}$ using bandpass filters (Kristoffersen et al., 2016).

\section{RNA-Seq Analysis}

Three independent samples exposed to $2.5 \mathrm{mM} \mathrm{H}_{2} \mathrm{O}_{2}$ for 2 days were frozen with liquid nitrogen and ground using a mortar and pestle. Total RNA was isolated using TRIzol reagent (Invitrogen). Three biological replicates of each sample were used for RNASeq. RNA quality was assessed by an Agilent 2100 bioanalyzer using a RNA 6000 Nano Chip (Agilent Technologies, Amstelveen, Netherlands), and RNA quantification was made using ND-2000 Spectrophotometer (Thermo Inc., DE, United States).

For control and test RNAs, rRNA was removed from each $5 \mu \mathrm{g}$ samples of total RNA using Ribo-Zero Magnetic kit (Epicenter, Inc., United States). Library construction was conducted using a SMARTer Stranded RNA-Seq Kit (Clontech lab Inc., CA, United States) according to the manufacturer's instructions. First, a strand cDNA library is synthesized using a modified N6 primer. When the SMARTScribe Reverse Transcriptase reaches the $5^{\prime}$ end of the RNA fragment, the enzyme's terminal transferase activity adds some additional nucleotides to the $3^{\prime}$ end of the cDNA. The carefully designed SMARTer Stranded Oligo base pairs with nontemplated nucleotides, creating an extended template to enable the SMARTScribe RT to continue replication to the end of the oligonucleotide. The resulting full-length, single-stranded (ss) cDNA contains the complete $5^{\prime}$ end of the mRNA, as well as sequences that are complementary to the SMARTer Stranded Oligo. cDNA is generated to release the library from the beads, and the library is then amplified. Barcodes were introduced when the library was amplified. High throughput sequencing was performed as paired-end sequencing using HiSeq 2500 (Illumina, Inc., United States).

Bacterial-Seq reads were mapped using Bowtie2 software to obtain the alignment file. Differentially expressed genes were determined based on counts from unique and multiple alignments using EdgeR within R version 3.2.2 (R Development Core Team, e-biogen, South Korea) using BIOCONDUCTOR version 3.0 (Gentleman et al., 2004). The alignment file was used for assembling transcripts. A global normalization method was used for comparisons between samples. The sample was repeated three times and the fold change was calculated as the average value. Gene classification was based on searches performed using DAVID $^{2}$. The GEO accession number is GSE122841.

\section{Statistical Analysis}

All of the OT strain biochemical results were calculated relative to those of the WT and neutral-site vector (NS) strains grown under normal conditions, which were defined as $100 \%$. Comparisons between individual data points were performed using Student's $t$-test with a $P<0.05$ being considered significant. All experiments were carried out at least in triplicate, and all results are expressed as the mean $\pm \mathrm{SD}$.

\section{RESULTS}

\section{OsTPX Gene Overexpressing Transgenic Rice Plants Improved $\mathrm{H}_{2} \mathrm{O}_{2}$ Stress Tolerance}

To facilitate the development of genetic engineering strategies to improve tolerance to abiotic stresses in plants, we previously identified the rice (O. sativa $\mathrm{L}$. Ilmi) stress-responsive OsTPX gene and showed that it functions in yeast (Kim et al., 2013). To study the potential of OsTPX gene enhancing tolerance to other abiotic stresses such as $\mathrm{H}_{2} \mathrm{O}_{2}$, we produced transgenic rice plants expressing the OsTPX cDNA under the control of the maize ubiquitin promoter and nos terminator (Figure 1A). Under oxidative stress, the phenotype of OsTPX gene overexpression in transgenic rice (TGR) plants was superior to that of the WT (Figure 1B). Overexpression of the OsTPX gene was verified by detecting the mRNA and protein levels (Figure 1C). We

\footnotetext{
${ }^{2}$ http://david.abcc.ncifcrf.gov/
} 
A

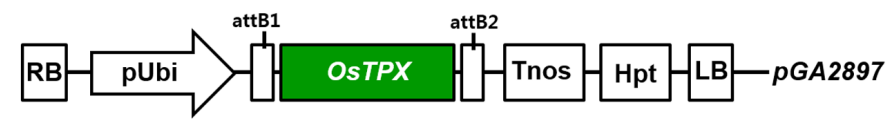

B
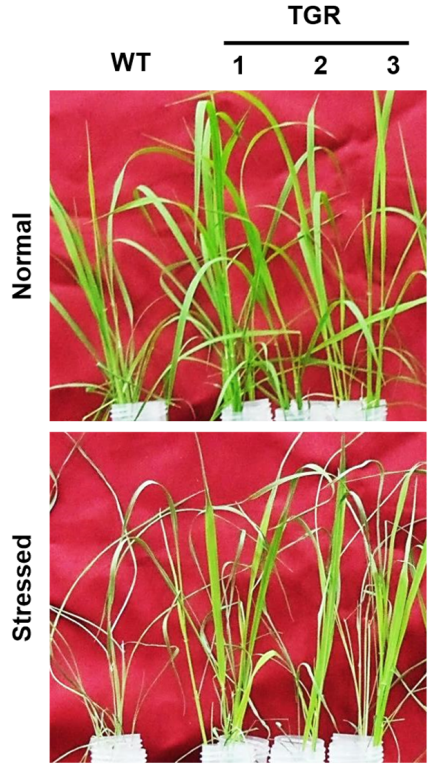

C
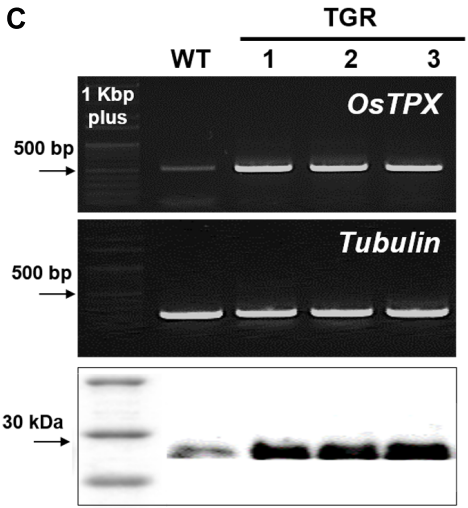

D
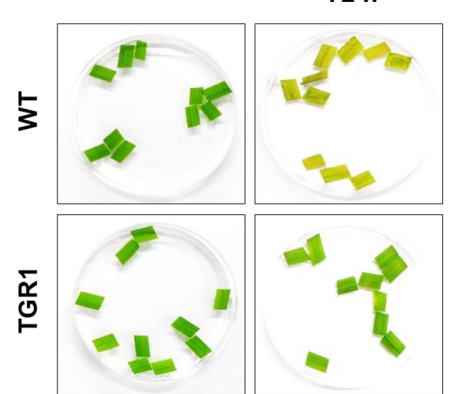

芷

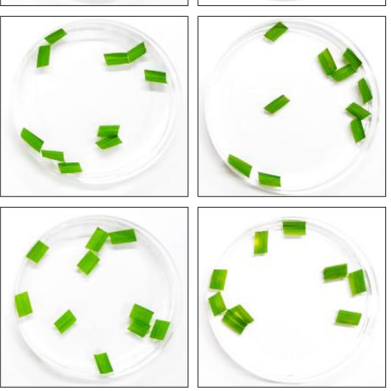

E

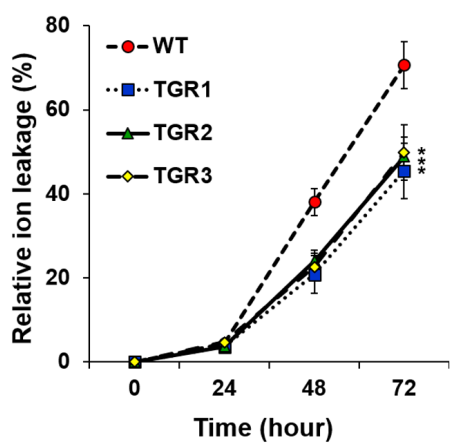

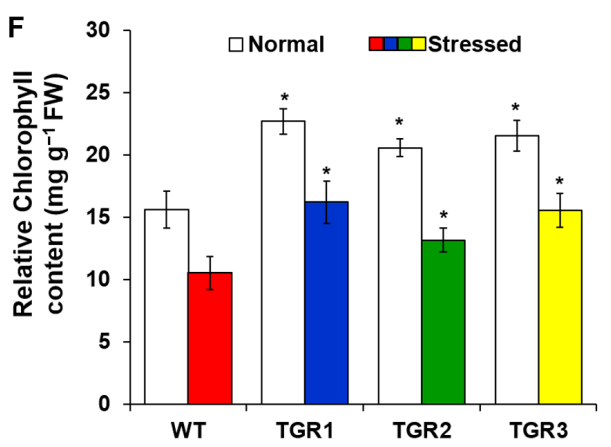

G

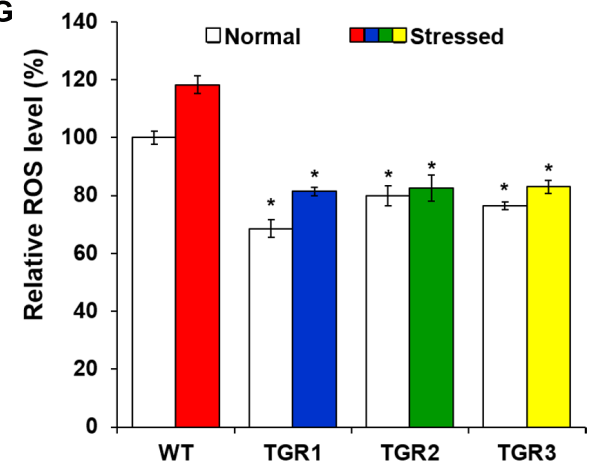

H

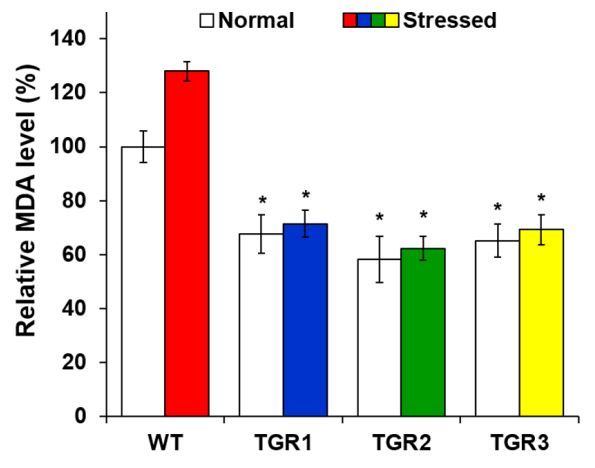

FIGURE 1 | Tolerance of OSTPX-expressing transgenic rice under $\mathrm{H}_{2} \mathrm{O}_{2}$ stress. Rice seedlings were grown under greenhouse conditions (25-30 ${ }^{\circ} \mathrm{C}$ ) and experimental samples were obtained from 4-week old seedlings. (A) Schematic diagram of the OsTPX expression chimeric gene construct, pUbi::OsTPX. OsTPX gene is under the control of the maize ubiquitin promoter ( $\left(\mathrm{Ubi}_{\text {) }}\right.$, nos terminator (Tnos) and linked to the antibiotic resistance gene, hygromycin (hgh). LB, left border; $\mathrm{RB}$, right border; attB1 and attB2, the Gateway recombination sites in pGA2897 binary vector. (B) Stress phenotype of OsTPX-overexpressing transgenic rice (TGR) and wild-type (WT) plants in medium containing $50 \mathrm{mM} \mathrm{H}_{2} \mathrm{O}_{2}$ after 3 days. (C) Gene expression was determined using semi-qRT-PCR with OsTPX (245 bp) tubulin (220 bp) as the positive control and western blot with anti-TPX. One kb plus marker and protein color marker were used to determine band size. (D,E) Relative ion leakage was measured from leaf disks of rice plants floating in $10 \mu \mathrm{M} \mathrm{MV}$ solution. Leaf disks were incubated at $25^{\circ} \mathrm{C}$ for $72 \mathrm{~h}$. The ion leakage percentages were calculated based on $100 \%$ of the values obtained after autoclaving. (F) Chlorophyll content, (G) ROS levels, and (H) MDA levels were determined as a measure of ROS scavenging ability. Error bars indicate \pm SD of three independent experiments. Asterisks indicate significant differences between treatments as estimated by Student's $t$-test $(P<0.05)$.

examined ion leakage in leaves because ROS-induced stress disrupts cell membranes and releases cytoplasmic solutes. TGR plants were significantly less damaged than the control WT rice plants at each time interval following $\mathrm{H}_{2} \mathrm{O}_{2}$ treatment (Figures 1D,E). We also examined chlorophyll content, which was related to the photosynthetic ability of the leaf disks following oxidative stress treatment. As shown in Figure 1F, all the TGR plants exhibited higher chlorophyll content both with and without exposure to oxidative stress compared to that of the control WT plants. Moreover, both TGR and WT plants showed significantly increased ROS production under stress conditions, but the level of ROS was approximately $40 \%$ lower in TGR plants 
compared to the control WT plants (Figure 1G). To estimate the lipid peroxidation levels, the MDA content of TGR and WT plants were analyzed under $\mathrm{H}_{2} \mathrm{O}_{2}$ stress conditions. The increase in MDA content was more pronounced in control WT rice plants than it was in TGR rice plants (Figure 1H), suggesting that overexpressing OsTPX gene in TGR plants could protect the plant cell membrane from oxidative damage by enhancing ROS scavenging activity. These results showed that the OsTPX gene expression improved oxidative stress tolerance of the TGR plants.

\section{Amino Acid Sequence Alignment}

Multiple sequence alignment was performed to examine the amino acid sequence motifs of OsTPX, using known TPX sequences as described in the Materials and Methods. Pairwise alignment of OsTPX and other TPXs were conducted using BLAST software. OsTPX showed 73, 50, 74, 73, 76, 73, and 92\% similarity to S. elongatus TPX (SeTPX), Saccharomyces cerevisiae TPX (ScTPX), Anabaena sp. TPX (AnTPX), Microcystis aeruginosa TPX (MaTPX), Thermosynechococcus elongatus TPX (TeTPX), Acaryochloris marina TPX (AmTPX), and A. thaliana TPX (AtTPX), respectively (Figure 2A). All of these sequences contain two conserved catalytic peroxidase cysteines, Cys114 and Cys236 (Figure 2A, green backgrounds), which likely form a disulfide bond with 2-Cys Prxs. SeTPX also possesses a highly conserved active-site region containing Thr111, Trp149, and Trp240 residues (FTFVCPT, AW, W; blue backgrounds) that are likely involved in peroxide reduction. Sequence alignment also shows the presence of TPX conserved motifs GGLG (Gly-GlyLeu-Gly, red background) and YF (Tyr-Phe, red background), which are found in cyanobacteria but are absent in most prokaryotes (Pascual et al., 2010). Cyanobacterial TPXs contain the GGLG and YF conserved domains, which protect the active site from reacting with peroxides (Sayed and Williams, 2004; Pascual et al., 2010). These results show that the OsTPX protein contains the cysteines required for disulfide bond formation and the conserved active-site regions found in amino acid sequences of other TPXs. We constructed a phylogenetic tree containing the SeTPX (accession no. AF492495.1), which is 73\% homologous to OsTPX (accession no. AK068919.1) (Figure 2B). The phylogenetic tree shows the evolutionary relationship between rice and cyanobacterial TPX genes. Thus, we selected the rice plant OsTPX gene to verify the function of the TPX gene for increasing cell defense regulatory networks through the cellular redox homeostasis in S. elongatus PCC 7942.

\section{Developing Genetically Transformed OsTPX-Expressing S. elongatus (OT) Strain}

An OT strain was constructed to evaluate $\mathrm{H}_{2} \mathrm{O}_{2}$-induced oxidative stress tolerance. The heterologous OsTPX gene was cloned into the neutral site II cyanobacterial expression vector pCV0069 under the control of the IPTG-inducible promoter (Ptrc) (Figure 3A). Resistance to oxidative stresses was evaluated in cyanobacterial $S$. elongatus strains transformed with the pCV0069::OsTPX plasmid containing the heterologous OsTPX gene and the $p C V 0069$ vector alone. The genotypes were confirmed by PCR using primers flanking the OsTPX gene (Supplementary Table S2), which resulted in the expected fragment size of 834 bp (Figure 3B and Supplementary Table S1). To explore whether the OsTPX gene was effectively expressed, a semi quantitative RT-PCR analysis was performed using primers targeted inside the OsTPX gene (Supplementary Table S2), which resulted in the expected fragment size of $278 \mathrm{bp}$ in the OT strain. However, no signal was detected in strains
A

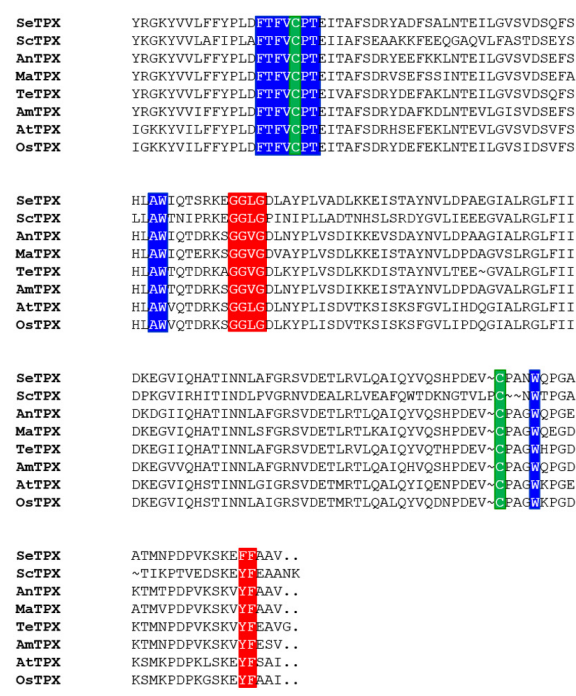

B

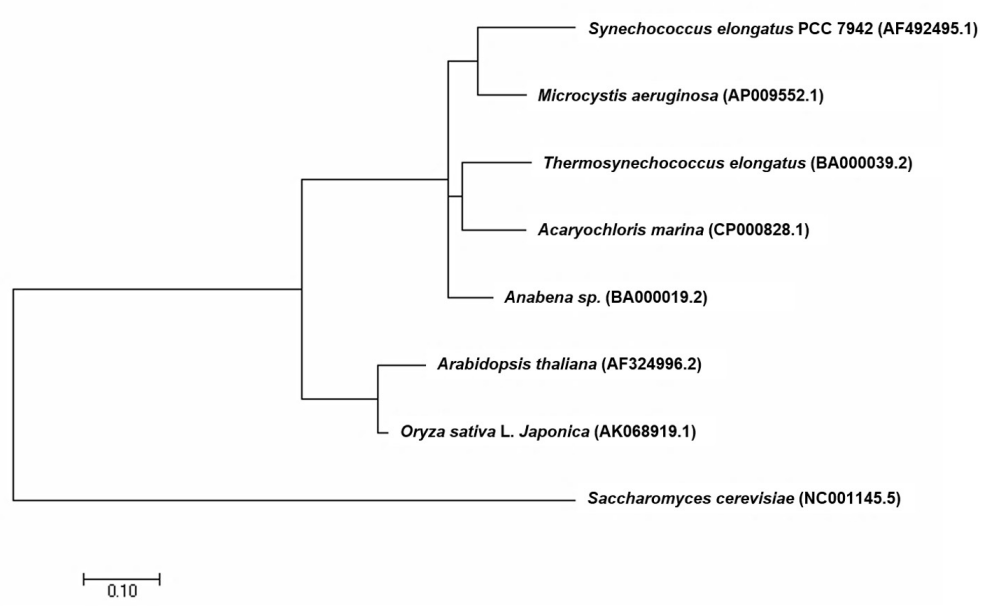

FIGURE 2 | Alignment of TPXs. (A) Alignment showing highly conserved active site regions and highly conserved redox-active disulfide bridge cysteine. Backgrounds indicate: TPX active site regions with GGLG and YF (red backgrounds), FTFVCPT, AW, and W (blue backgrounds); cysteine residues involved in disulfide bridges (C and C; green backgrounds) (B) phylogenetic tree of OsTPX and other TPXs. 
A

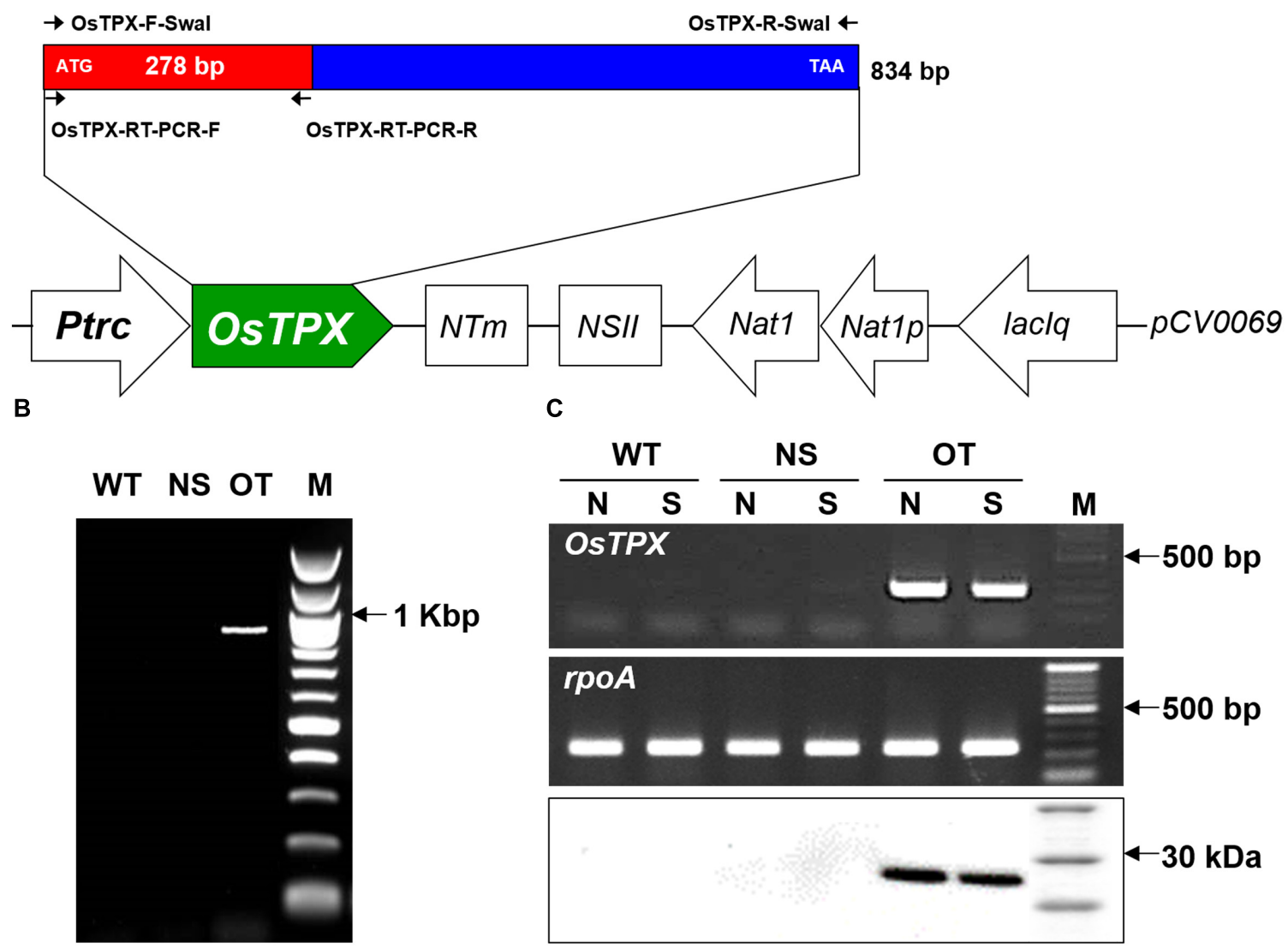

FIGURE 3 | Construct of the OT strain and confirm gene expression. (A) Schematic diagram showing the expression of OsTPX in S. elongatus. Ptrc, IPTG-inducible promoter; OsTPX, TPX gene of O. sativa; Nat, nourseothricin antibiotic resistance; laclq, lactose repressor. Arrows indicate direction of each gene. (B) PCR of OSTPX gene in transgenic S. elongatus (OT) to confirm genotype. (C) Expression of OsTPX gene was confirmed using semi-qRT-PCR (upper two panels) and western blotting (lower panel). The rpoA transcript was used as a control in the transcriptional analysis. N, normal condition; S, stressed condition.

transformed with the empty NS and the WT strain (Figure 3C and Supplementary Table S1). We also performed western blot analysis to determine if the OsTPX gene was properly translated. The OT strain grown under $\mathrm{H}_{2} \mathrm{O}_{2}$ stress for 2 days showed the presence of a single band in the western blotting analysis using the plant anti-TPX antibody. The predicted molecular weight of the identified OsTPX protein was $28.079 \mathrm{kDa}$. No signal was detected in the NS and WT strains under the same conditions (Figure 3C). As a result, we transformed S. elongates with a transgene constructed from the heterologous OsTPX cDNA, regulated by a strong constitutive Ptrc promoter. These results indicate that the heterologous OsTPX gene and protein was expressed in the OT strain under control of the Ptrc promoter.

\section{An OT Strain Showed Tolerance to $\mathrm{H}_{2} \mathrm{O}_{2}$ Stress Condition}

Stress tolerance was measured using growth kinetics and colony formation on plates. IPTG $(0.2 \mathrm{mM})$ was added to the NS and OT lines to activate the Ptrc promoter just before the stress treatment. The OT strain grew better than the NS and WT strains under
$\mathrm{H}_{2} \mathrm{O}_{2}$ stress (Figures 4A,B). The NS and WT strains showed pigment losses on day 9, which was 2 days after exposure to $\mathrm{H}_{2} \mathrm{O}_{2}$ stress, and were completely bleached by day 12 ; whereas the OT strain showed relatively less pigment loss on days 9 and 12, and showed regrowth at 18 days (Figure 4B). As shown in Figures $\mathbf{4 A , B}$, the OT strain containing the heterologous OsTPX gene showed significantly increased tolerance to $\mathrm{H}_{2} \mathrm{O}_{2}$ stress. Stress response was also determined using a plate cellspotting assay. Exponentially growing OT, NS, and WT strains $\left(\mathrm{OD}_{730}=0.30-0.35\right)$ were exposed to $2.5 \mathrm{mM} \mathrm{H}_{2} \mathrm{O}_{2}$ for 2 days and then serial dilutions were spotted on agar-solidified BG11 medium (Figure 4C). The OT strain showed higher cell viability than that of the NS and WT strains following exposure to high concentrations of $\mathrm{H}_{2} \mathrm{O}_{2}$. These results show that the heterologous OsTPX gene expression in the OT strain enhanced oxidative stress tolerance.

\section{Analysis of ROS Level and Cell Viability Under the $\mathrm{H}_{2} \mathrm{O}_{2}$ Stress}

To investigate the effects of oxidative stress produced by $\mathrm{H}_{2} \mathrm{O}_{2}$ generated ROS, ROS levels were analyzed in vitro and in vivo 

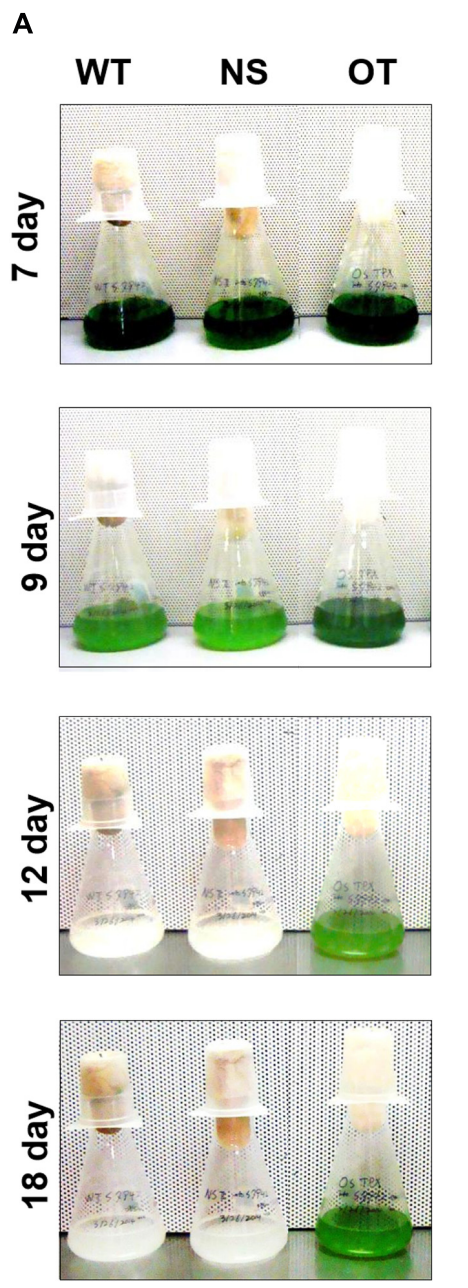

B

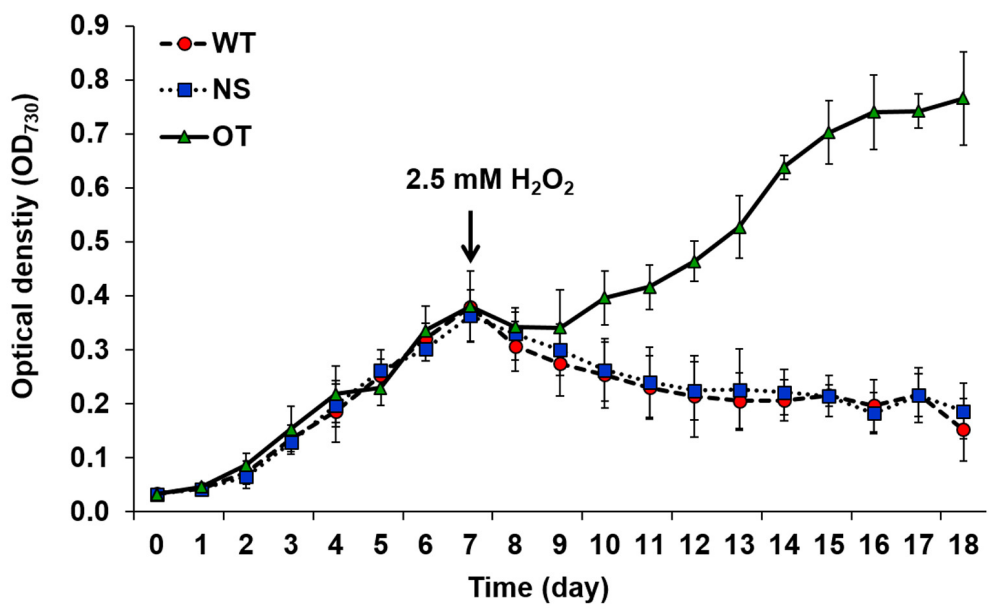

C

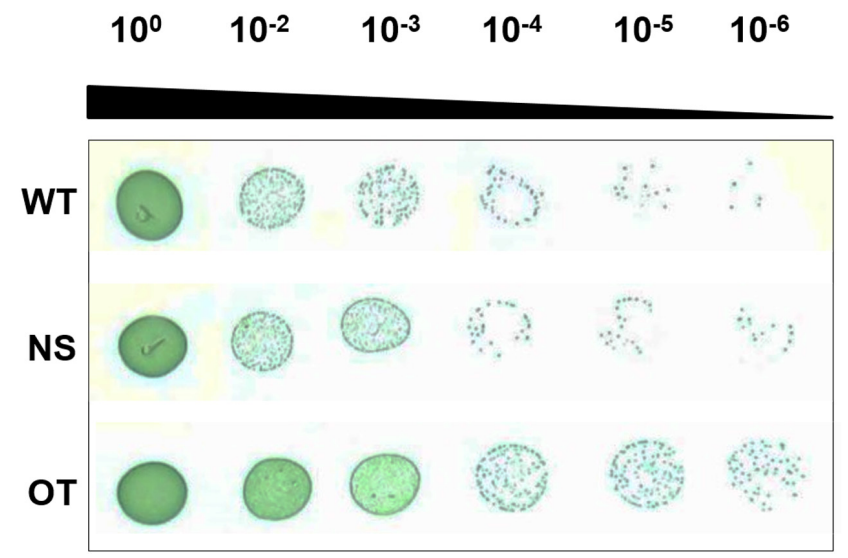

FIGURE 4 | Analysis of WT, NS, and OT strains $\mathrm{H}_{2} \mathrm{O}_{2}$ stress tolerance. (A) Phenotypes, (B) growth phase of each strains, and (C) spotting assay and error bars calculated from the SD of three independent experiments. WT, wild-type; NS, empty neutral-site vector strain; OT, overexpression transgenic strain. Error bars indicate \pm SD of three independent experiments. Asterisks indicate significant differences between treatments as estimated by Student's $t$-test $(P<0.05)$.

in the OT, NS, and WT strains. The redox state was determined based on the cellular ROS level assayed with the cytosolic oxidant-sensitive probe $2^{\prime}, 7^{\prime}$-dichlorodihydrofluorescein diacetate (DCFHDA), which measures the oxidative conversion of DCFHDA to the highly fluorescent compound dichlorofluorescein (DCF). NS and OT strains were added to $0.2 \mathrm{mM}$ IPTG for Ptrc promoter activation just before exposure to $\mathrm{H}_{2} \mathrm{O}_{2}$. The three strains showed increased DCF fluorescence following exposure to $2.5 \mathrm{mM} \mathrm{H}_{2} \mathrm{O}_{2}$ for 2 days, but the fluorescence intensity of the probe was more pronounced in the control NS and WT strains than in the OT strain (Figure 5A). In a biochemical assay using the ferrous oxidationxylenol orange (FOX) reagent, cellular ROS levels in the OT strain were approximately twofold lower than those in the $\mathrm{NS}$ and WT strains in the presence of $\mathrm{H}_{2} \mathrm{O}_{2}$ (Figure 5B). No differences were observed among the cells under normal conditions (Figure 5B, white columns). Furthermore, lower ROS production in the OT strain resulted in less MDA accumulation by lipid peroxidation compared to levels in the NS and WT strains (Figure 5C). MDA accumulation was 1.2-fold higher in NS and WT strains than in the OT strain. Additionally, the total biomass yield of the OT strain was 2.5-fold higher than that of the NS and WT strains subjected to oxidative stress (Figure 5D). Therefore, our results show that heterologous OsTPX gene expression in the OT strain conferred tolerance against oxidative stress high-yield biomass production compared to that observed in the control NS and WT strains.

\section{OT Strain Showed Improved Photosynthesis Capacity and Chlorophyll Content Under $\mathrm{H}_{2} \mathrm{O}_{2}$ Stress Conditions}

All indicators of photosynthetic capacity were enhanced in the OT strain in the presence of $\mathrm{H}_{2} \mathrm{O}_{2}$ compared to those in the control NS and WT strains (Figure 6). NS and OT strains 
A

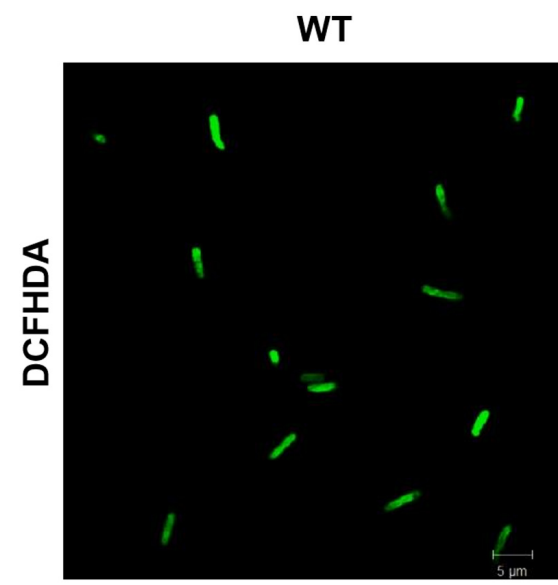

B

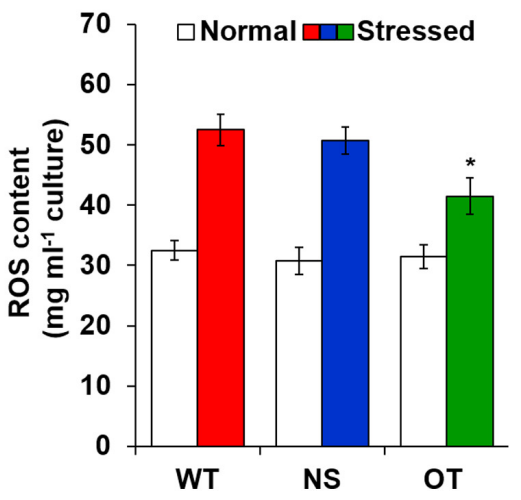

C
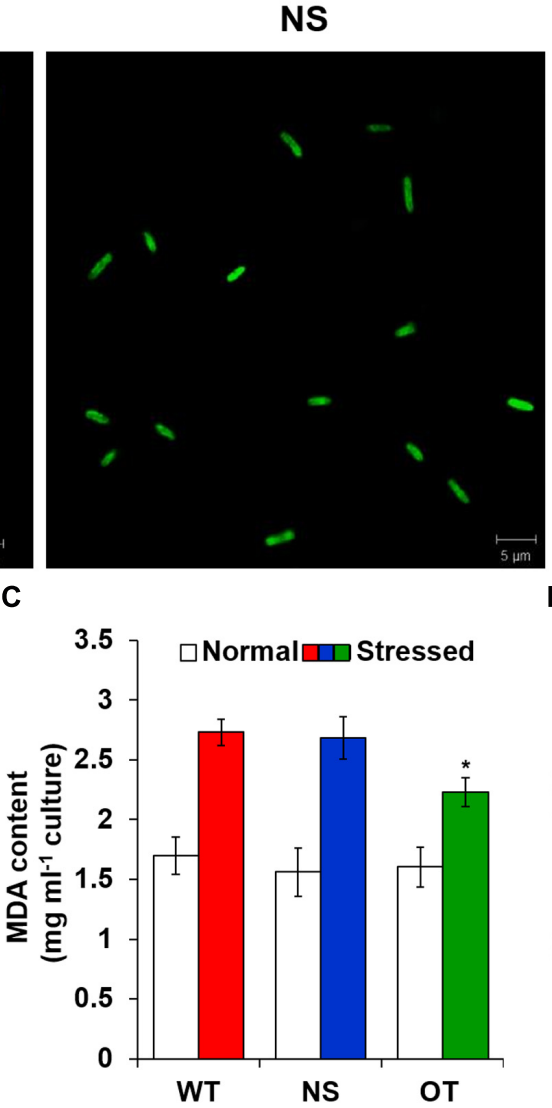
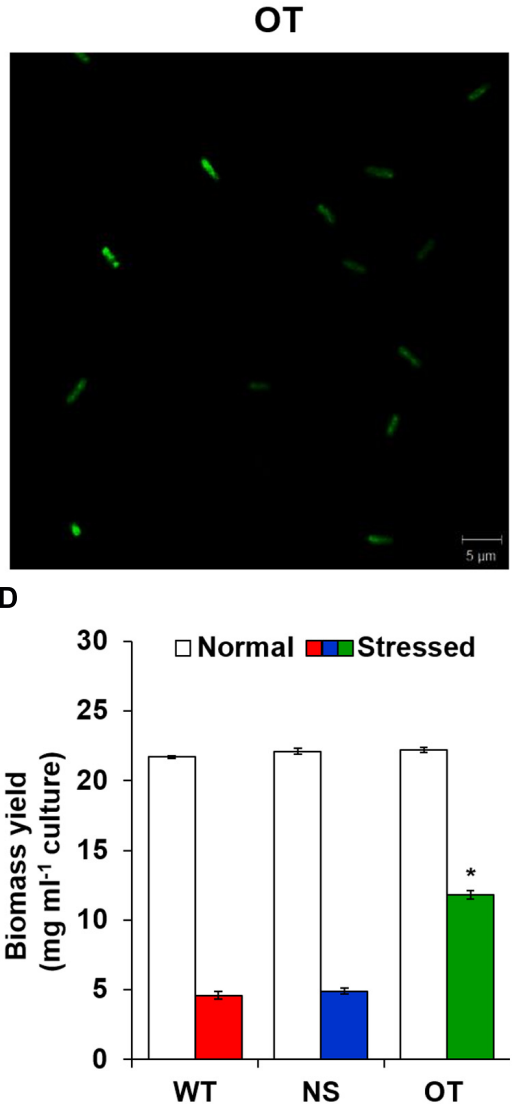

FIGURE 5 | Measure ROS, MDA levels and dry weight under the oxidative stress. (A) Detection of DCFHDA fluorescence using confocal microscopy. (B) Intracellular ROS levels determined by FOX reagent. (C) The level of lipid peroxidation determined by MDA using a TBA assay. (D) Biomass yield measured after growth in the presence of high $\mathrm{H}_{2} \mathrm{O}_{2}$ concentrations. Error bars indicate SD of three independent experiments. Error bars indicate \pm SD of three independent experiments.

Asterisks indicate significant differences between treatments as estimated by Student's $t$-test $(P<0.05)$.

were added to $0.2 \mathrm{mM}$ IPTG for Ptrc promoter activation just before $\mathrm{H}_{2} \mathrm{O}_{2}$ stress exposure. The major chlorophyll fluorescence parameters measured (Gorbe and Calatayud, 2012) were; maximal chlorophyll fluorescence intensity $\left(F_{\mathrm{m}}\right)$, effective quantum yield of photochemical energy conversion in photosystem II (QY), non-photochemical quenching (NPQ), and chlorophyll fluorescence decrease ratio $\left(R_{\mathrm{Fd}}\right)$ (Figure 6A). These fluorescence parameters and ratios were measured in a darkadapted state to determine the functionality of photosystem II. For all parameters, the OT strain showed higher levels compared to those observed in the NS and WT strains (Figure 6A). Additionally, measurement of chlorophyll content showed smaller loss of chlorophyll in the OT strain than in the NS and WT strains under normal and stress conditions (Figure 6B). Variable to maximum fluorescence $\left(F_{\mathrm{V}} / F_{\mathrm{m}}\right.$, photochemical yield), performance index for photosynthesis $\left(\mathrm{Pi}_{\mathrm{ABS}}\right)$, and dissipation energy per active reaction center $\left(\mathrm{DI}_{0} / \mathrm{RC}\right)$, were three indicators measured under the treated and untreated $\mathrm{H}_{2} \mathrm{O}_{2}$ conditions to provide a quantitative analysis of photosynthetic properties (Figures 6C-E). In particular, the $F_{\mathrm{v}} / F_{\mathrm{m}}$ ratio was significantly increased in the OT strain (Figure 6C) compared to that in the control strains. Additionally, $\mathrm{Pi}_{\mathrm{ABS}}$, which is the performance index for energy conservation from photons absorbed by the PSII antenna until the reduction of PSI acceptors, was enhanced in the OT strain (Figure 6D). The $\mathrm{DI}_{0} / \mathrm{RC}$ ratio declined in the OT strain, showing that less absorbed light energy was dissipated as fluorescence (Figure 6E), which indicates a better photosynthetic efficiency compared to the NS and WT strains under normal and $\mathrm{H}_{2} \mathrm{O}_{2}$ stress conditions (Figure 6).

\section{Effect of OsTPX Gene Expression on the Cyanobacterial Antioxidant Defense System}

The OT strain exhibited improved intracellular ROS levels, redox homeostasis, photosynthetic ability, membrane stability, and growth during cultivation in the presence of $\mathrm{H}_{2} \mathrm{O}_{2}$. Therefore, we profiled gene expression to identify the mechanisms underlying OsTPX-mediated tolerance against $\mathrm{H}_{2} \mathrm{O}_{2}$ stress. OT strains were added to $0.2 \mathrm{mM}$ IPTG for Ptrc promoter activation just before $\mathrm{H}_{2} \mathrm{O}_{2}$ stress exposure. RNA-sequencing 
A

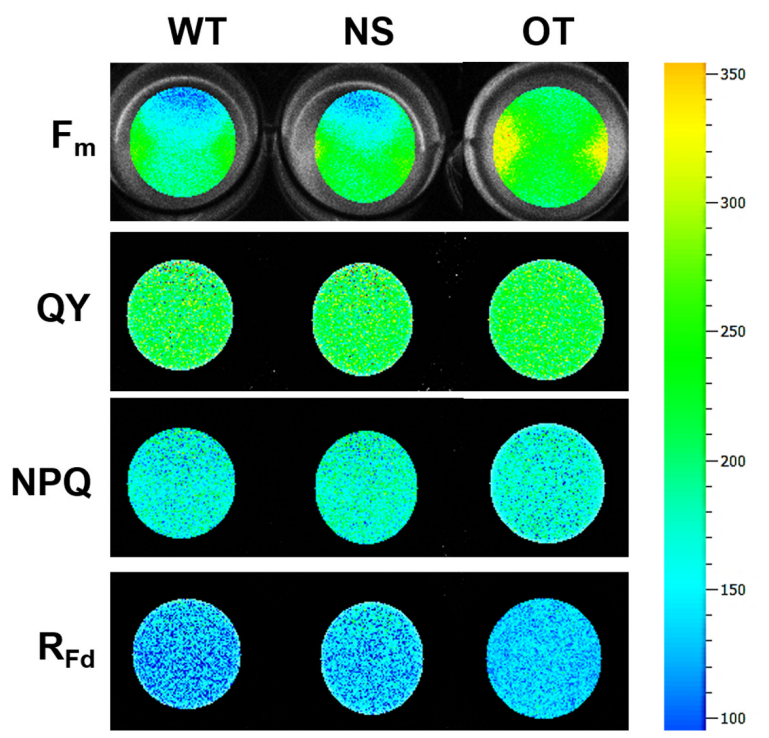

C

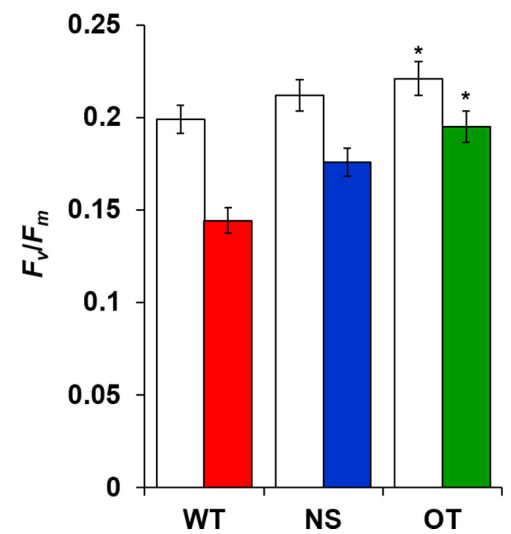

B

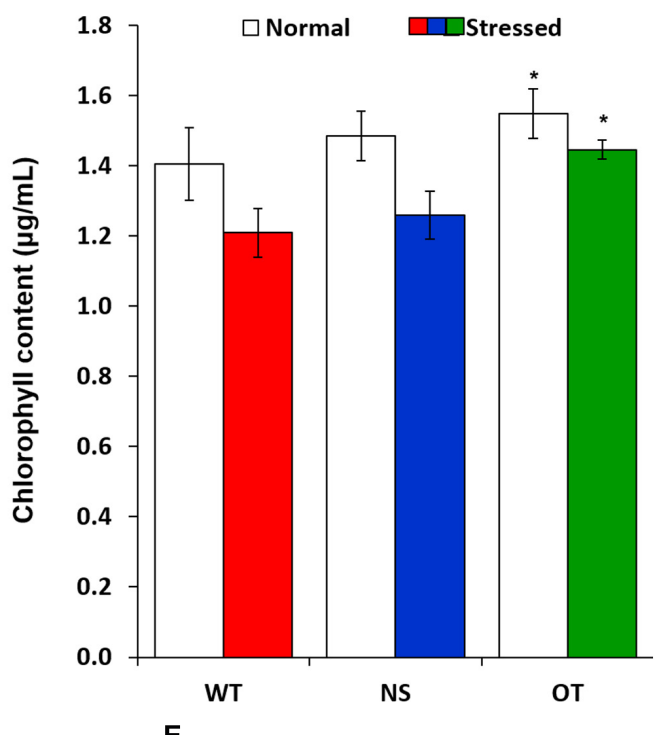

E

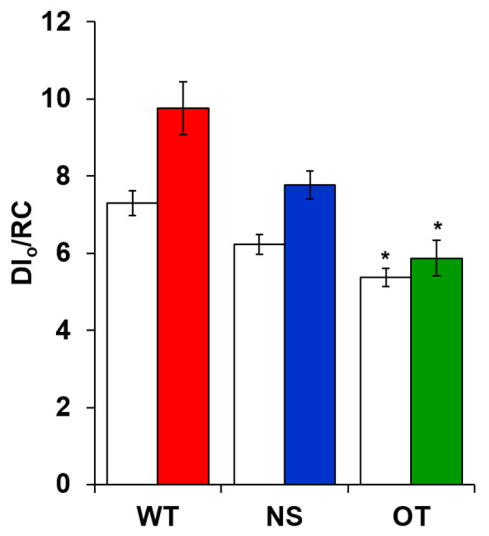

FIGURE 6 | Comparison of chlorophyll fluorescence in cyanobacterial cells grown under normal and $\mathrm{H}_{2} \mathrm{O}_{2}$ stress conditions. (A) Fluorescence images of $F_{m}$, QY, $\mathrm{NPQ}$, and $R_{\mathrm{Fd}}$ in WT, NS, and OT strains. The higher efficiency rates are depicted in red and the lower rates in blue. (B) Chlorophyll content, (C) $F_{\mathrm{V}} / F_{\mathrm{m}}$, (D) $\mathrm{Pi} \mathrm{ABS}_{\mathrm{B}}$, and (E) Dlo/RC. $F_{m}$, maximum fluorescence; QY, quantum yield of photochemical energy conversion in photosystem II; NPQ, non-photochemical quenching; $R_{F d}$, chlorophyll fluorescence decrease ratio; $F_{\mathrm{v}} / F_{\mathrm{m}}$, photochemical yield; $\mathrm{Pi}_{\mathrm{ABS}}$, performance index for photosynthesis; $\mathrm{DI} / \mathrm{RC}$, value of the energy dissipated per reaction center. Error bars indicate $\pm \mathrm{SD}$ of three independent experiments. Asterisks indicate significant differences between treatments as estimated by Student's t-test $(P<0.05)$.

(RNA-Seq) data identified 18 genes that were upregulated in the OT strain after treatment with $2.5 \mathrm{mM} \mathrm{H}_{2} \mathrm{O}_{2}$ for 2 days (Figure 7). All gene fold results were calculated as OT/WT fold. The results showed that expression of OsTPX gene increased redox balance (ferredoxin, 5.193; ferredoxin-thioredoxin reductase, 2.605; catalase peroxidase, 2.457; flavodoxin2, 2.051; glutathione peroxidase, 1.825 ; flavodoxin, 1.745), photosynthesis (chlorophyll synthase ChlG, 2.359; magnesium protoporphyrin IX methyltransferase, 1.866; high light inducible protein, 1.741; magnesium-protoporphyrin IX monomethyl ester cyclase, 1.508), ion homeostasis (potassium channel protein, 2.338; ABC transporter ATP-binding protein, 2.209; $\mathrm{Fe}^{3+} \mathrm{ABC}$ transporter substrate-binding protein; hemolysin-type calcium-binding repeat, $2.115 ; \mathrm{K}^{+}$transporter, 2.102), and molecular chaperone (molecular chaperone DnaJ, 2.083; molecular chaperone DnaJ, 1.811; molecular chaperone HtpG, 1.686) in the OT strain compared to the WT strain. These results suggest that heterologous OsTPX gene expression in S. elongatus PCC 7942 improved cell defense regulatory networks from oxidative damage, and maintained the balance of cellular redox and photosynthesis.

\section{DISCUSSION}

Many studies have been performed to examine the effect of TPX gene overexpression on cellular metabolism for a wide variety of organisms (Chae et al., 1994; Yamamoto et al., 1999; 


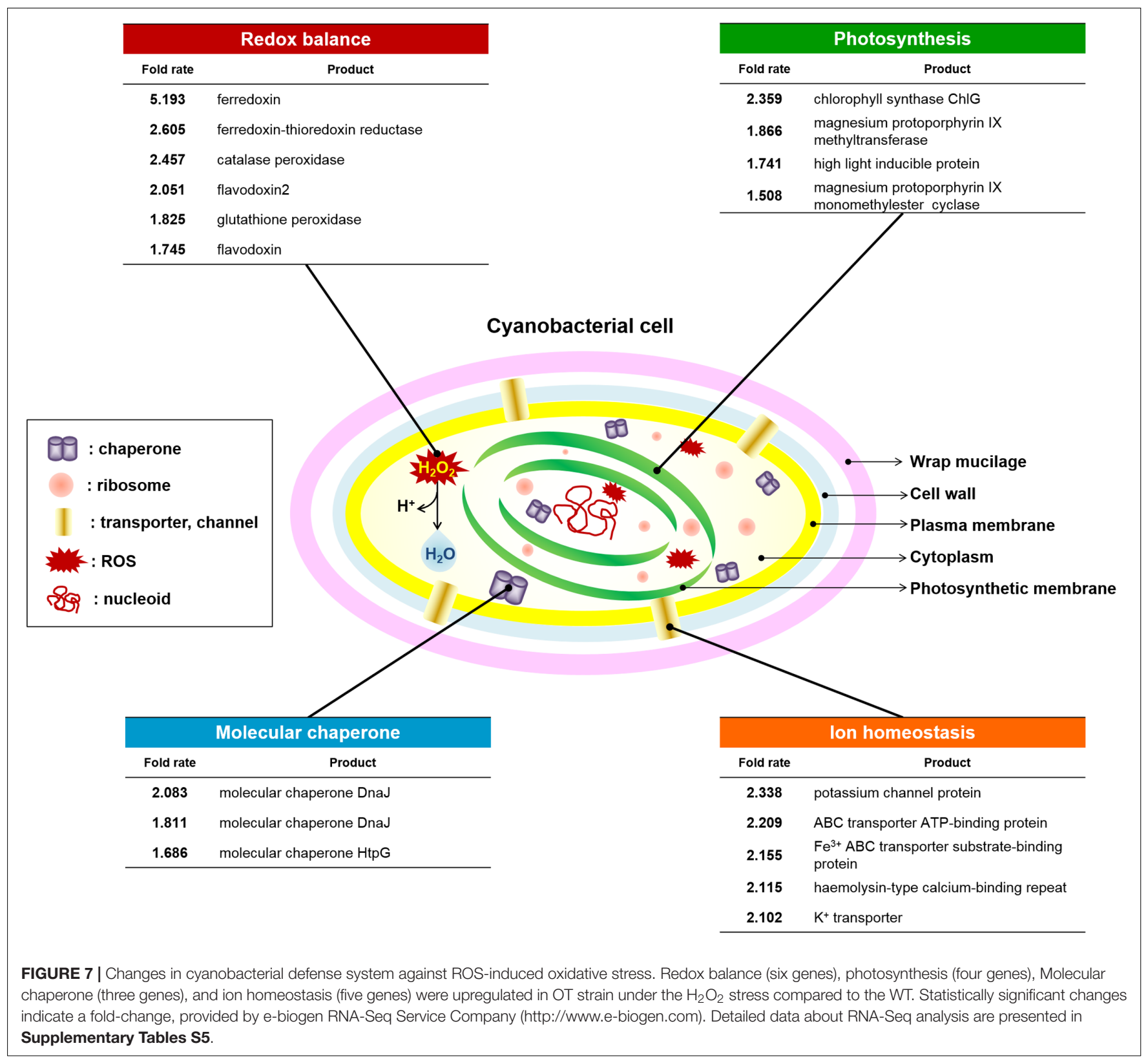

Berggren et al., 2001; Broin and Rey, 2003). In previous studies, analysis of transgenic Arabidopsis with reduced TPX amounts demonstrated that the TPX protects chloroplast proteins from oxidative damage. Partial suppression of TPX expression caused impairment of photosynthesis and increased oxidative damage of chloroplast proteins during early plant development (Dietz et al., 2002). Similar results were found in the present study, where developed TGR plants overexpressed the OsTPX gene under the control of maize ubiquitin promoter (Figure 1A), confirming that the expression was at the mRNA and protein levels (Figure 1C). TGR plants conferred acquired $\mathrm{H}_{2} \mathrm{O}_{2}$ stress tolerance (Figure 1B) by improving higher cell stability and chlorophyll content (Figures 1D-F). Additionally, maintaining low MDA and ROS levels in rice plant cells (Figures $\mathbf{1 G}, \mathbf{H}$ ) indicated that TGR plants had an enhanced stress response than did the WT plants. However, the role of TPX gene in oxidative stress has not been studied in S. elongatus PCC 7942. To confirm the above results with other strains, including $S$. elongatus PCC 7942, the current study was conducted to determine if the expression of the OsTPX gene in S. elongatus enhanced its tolerance to $\mathrm{H}_{2} \mathrm{O}_{2}$-induced oxidative stress.

The enhancement of stress tolerance in the OT strain may be due to the heterologous OsTPX gene having similar functions through the highly conserved active regions of the protein sequences of OsTPX and cyanobacterial TPX. Interestingly, amino acid sequence alignment indicated that OsTPX shares a highly conserved active-site region; described green backgrounds (C), red backgrounds (GGLG, AW), and blue backgrounds 
(FTFVCPT, AW, W) in Figure 2A (Wood et al., 2003; Sayed and Williams, 2004; Moon et al., 2005; Pascual et al., 2010; Kim et al., 2013). Two catalytic cysteine residues (Cys 114 and Cys 236) of TPX could have important roles in neutralizing toxic ROS, which is consistent with a previous study that found human TPXs were involved in detoxifying ROS and protected cells from oxidative stress (Schröder et al., 2000). The susceptibility to overoxidation has been considered specific for TPX and depends on the presence of two motifs, GGLG and YF, of these proteins (Wood et al., 2003). Additionally, modification of Thr66, Trp99, and Trp89 of barley HvTPX (Thr116 in FTFVCPT, Trp149 in AW, and Trp240 is $\mathrm{W}$ of OsTPX) involved these residues in the conformational change (dimer to oligomer) that altered protein function (König et al., 2003). Notably, the previous study showed that other TPX-mutated strains exhibited decreased TPX activity, indicating that these residues are essential for the catalysis of Thr48 of poplar PtTPX (Thr111 in OsTPX), and Cys64 of barley HvTPX (Cys114 of OsTPX) (König et al., 2003; Rouhier and Jacquot, 2008). The phylogenetic tree also shows the evolutionary relationship between rice and cyanobacterial TPX genes (Figure 2B). Therefore, these highly conserved regions play a key role in TPX gene function. It can be expected that the OsTPX gene of rice plants functions in a cooperative role in the oxidative stress tolerance that has been observed in cyanobacteria.

To investigate whether the expression of the OsTPX gene affects oxidative stress in cyanobacteria, we transformed S. elongatus PCC 7942 with the OsTPX gene under the control of the Ptrc promoter, and confirmed its expression at the mRNA and protein levels (Figures 3A,C). Our results show that heterologous OsTPX gene expression can enhance tolerance of cyanobacteria to oxidative stress such as $\mathrm{H}_{2} \mathrm{O}_{2}$ (Figure 4). It has been reported that the heterologous TPX gene is able to improve stress tolerance in many organisms (Lee et al., 2000; Jing et al., 2006). This may explain why the OT strain showed better growth than the control NS and WT strains did in the presence of abiotic stresses, including major ROS-generating agents, such as; $200 \mathrm{mM} \mathrm{NaCl}$, a low $10^{\circ} \mathrm{C}$ temperature, $250 \mu \mathrm{E}$ high-intensity light, and $20 \%$ sodium dodecyl sulfate (SDS) (Supplementary Figure S1). Previous studies found that the TPX gene increased salt and low temperature tolerance in Arabidopsis (Jing et al., 2006); and that the loss of TPX gene function in Synechocystis sp. resulted in significantly late grow rates compared to control wild-type strains under high light conditions (Kobayashi et al., 2004). In other studies, the TPX gene functioning as a chaperone indicated that it was effective in preventing protein aggregation induced by SDS stress (Jang et al., 2004; Messina et al., 2014). Taken together, heterologous OsTPX gene expression enhanced tolerance to abiotic stresses by eliminating ROS-induced oxidative stress.

As mentioned above, regulating $\mathrm{H}_{2} \mathrm{O}_{2}$ balance is very important to redox homeostasis in cell peroxidation. To investigate the effects of oxidative stress such as $\mathrm{H}_{2} \mathrm{O}_{2}$-generated ROS, ROS levels were measured in vitro and in vivo in the WT, NS, and OT strains (Figures $\mathbf{5 A}, \mathbf{B}$ ). Low ROS production in the OT strain resulted in less MDA accumulation by lipid peroxidation compared to that observed in the NS and WT strains. Therefore, the total biomass yield of the OT strain was decreased to a smaller extent upon exposure to oxidative stress (Figures 5C,D). These findings are consistent with a previous observation that the TPX gene is related to oxidative stress and could eliminate cellular damage caused by ROS in cyanobacteria (Klughammer et al., 1998; Stork et al., 2009; Pascual et al., 2010). Additionally, a gene disruption study showed that the TPX gene is essential for survival under oxidative stress conditions by maintain cell stability (Kobayashi et al., 2004). Thus, it can be speculated that heterologous OsTPX gene enhanced stress tolerance and biomass yield by preventing cell damage under the oxidative stress within S. elongatus PCC 7942.

Published studies have provided evidence of the relationship between stress tolerance and photosynthetic capacity, which is affected by TPX gene overexpression in several organisms (Nikkanen and Rintamaki, 2014; Brzezowski et al., 2015; Puerto et al., 2015; Guevara-Flores et al., 2017). For example, TPX gene expression conferred tolerance to long-day photoperiod and oxidative stresses by reducing the cellular ROS level in Debaryomyces hansenii (Chao et al., 2009) and Pichia methanolica (Puerto et al., 2015). We also found that the OT strain exhibited higher chlorophyll content (Figure 6B) and $F_{\mathrm{v}} / F_{\mathrm{m}}$ ratio under normal and $\mathrm{H}_{2} \mathrm{O}_{2}$ stress conditions (Figure $6 \mathrm{C}$ ), and also showed an increased photosynthetic efficiency based on the QY, NPQ, $R_{\mathrm{Fd}}$, and $\mathrm{Pi}_{\mathrm{ABS}}$ (Figures $6 \mathrm{~A}, \mathrm{D}$ ). In contrast, the $\mathrm{OT}$ strain showed decreased $\mathrm{DI}_{0} / \mathrm{RC}$ values (Figure $6 \mathrm{E}$ ), whereas the NS and WT strains exhibited considerably higher levels of energy dissipation than the OT strain under normal and $2.5 \mathrm{mM}$ $\mathrm{H}_{2} \mathrm{O}_{2}$ conditions. This phenomenon is assumed to be related to an increase in gene expression that involved photosynthetic metabolism (Figure 7 and Supplementary Table S3). A highlight inducible gene, perhaps induced by OsTPX gene expression, could play a critical role in the adaptation of cyanobacterium through an increase in chlorophyll, and by improving the repair of the photosynthetic apparatus (Zeng et al., 2002; Havaux et al., 2003). Furthermore, genes related to the chlorophyll biosynthesis pathway were increased more in the OT strain than the WT strain. Several genes such as chlorophyll synthase ChlG, magnesium protoporphyrin IX methyltransferase, and magnesium protoporphyrin IX monoethyl ester cyclase are involved in tetrapyrrole biosynthesis pathway, which is known as the chlorophyll biosynthesis pathway in plants (Brzezowski et al., 2015). Therefore, these results indicated that heterologous OsTPX gene expression induced chlorophyll biosynthesis, resulting in enhanced photosynthetic capacity in S. elongatus PCC 7942.

Reduced TRX also reduces the oxidized TPX by ROSinduced stress. These reactions are critical in protecting cells under oxidative stress conditions (Dietz, 2007). Our results, which included gene profiling of WT and OT strains under $\mathrm{H}_{2} \mathrm{O}_{2}$ stress, showed an increase in antioxidant genes such as catalase peroxidase and glutathione peroxidase compared with control strains (Figure 7 and Supplementary Tables S3, S5). In addition, electron shuttles harboring iron-sulfur clusters such as ferredoxin, ferredoxin-thioredoxin reductase, and flavodoxin were increased in the OT strain. Ferredoxin is an important molecule involved in the routes of cyclic electron flow that 
operate under physiological and stress conditions, and is also used as a reducing equivalent by TRX and ferredoxinthioredoxin reductase (Tognetti et al., 2006). In cyanobacteria, stress situations induce the synthesis of flavodoxin (Falk et al., 1995), an electron carrier flavoprotein that is not found in plants. The overexpression of flavodoxin in E. coli leads to an augmented tolerance toward various sources of oxidative stress (Zheng et al., 1999). These electron shuttles could be expected to maintain cellular homeostasis by regulating redox balance during electron transfer. However, those antioxidant and electron carrier genes show no differential expression levels between WT and OT strains under normal conditions (Supplementary Table S4). Interestingly, our results appear to show the level of cyanobacterial TRX $(S e T P X)$ is more similar to the OT strain, than to the WT strain under the normal and stress conditions (Supplementary Table S4). This phenomenon assumed that OsTPX is not affected by SeTPX under normal and stress conditions; however, the expression of related genes were upregulated in the presence of $\mathrm{H}_{2} \mathrm{O}_{2}$. These results indicated that the heterologous OsTPX gene affected higher expression levels of antioxidant and electron carrier genes under the $\mathrm{H}_{2} \mathrm{O}_{2}$ stress conditions. Consequently, the OT strain improved cell homeostasis by maintaining a redox balance when compared to the WT strain.

Taken together, these findings indicate that the expression of the OsTPX gene in rice plants and S. elongatus resulted in an improvement in stress tolerance to ROS-induced oxidative stress and enhanced photosynthetic ability. In addition, cell membrane stability and biomass yield increased in the OT strain when compared to the WT and NS strains. These effects were achieved by enhancing the balance of cellular redox homeostasis through the activity of heterologous OsTPX gene expression, which resulted in the expression of related genes in the redox balance, photosynthesis, ion homeostasis, and molecular chaperone. In conclusion, our results found that OsTPX gene expression of rice plants could improve the cell defense regulatory network through cellular redox homeostasis under the oxidative stress in S. elongatus PCC 7942. Therefore, future studies on the genetic and molecular functions of the OsTPX gene should focus on the interactions between plants and cyanobacteria, and their responses to various environmental conditions.

\section{REFERENCES}

Berggren, M. I., Husbeck, B., Samulitis, B., Baker, A. F., Gallegos, A., and Powis, G. (2001). Thioredoxin peroxidase-1 (peroxiredoxin-1) is increased in thioredoxin-1 transfected cells and results in enhanced protection against apoptosis caused by hydrogen peroxide but not by other agents including dexamethasone, etoposide, and doxorubicin. Arch. Biochem. Biophys. 392, $103-$ 109. doi: 10.1006/abbi.2001.2435

Broin, M., and Rey, P. (2003). Potato plants lacking the CDSP32 plastidic thioredoxin exhibit overoxidation of the BAS1 2-cysteine peroxiredoxin and increased lipid Peroxidation in thylakoids under photooxidative stress. Plant Physiol. 132, 1335-1343. doi: 10.1104/pp.103.02 1626

\section{AUTHOR CONTRIBUTIONS}

Y-SK, I-SK, JG, and H-SY designed the project and were involved in the writing of the manuscript. Y-SK and J-JK wrote the manuscript. Y-SK and S-IP carried out most of the experiments and analyzed the data. SD, JB, and AT participated in the discussion and critiqued the writing.

\section{FUNDING}

This work was supported by a grant from the Next-Generation BioGreen 21 Program (No. PJ01366701), Rural Development Administration, Korea, and the Basic Science Research Program through the National Research Foundation of Korea (NRF) funded by the Ministry of Education (2016R1A6A1A05011910), (2018R1D1A3B07049385), (2017R1A2B4002016), Korea, and the Advanced Biomass R\&D Center (ABC) of Global Frontier Project funded by the Ministry of Science and ICT (ABC-2015M3A6A2065698), Korea, and from the US NIH-NIGMS award number R01GM118815, United States (JG).

\section{ACKNOWLEDGMENTS}

We thank Susan S. Golden (University of California, San Diego [UCSD] and Center for Chronobiology [CCB]) for supplying $S$. elongatus strains. We also thank Benjamin Rubin, Ryan K. Shultzaberger, You Chen, Amy T. Ma, Mizuho Ota, Susan E. Cohen, Mark L. Paddock, Yong-Ick Kim, David G. Welkie, Roger Tseng, and Cigdem Sancar for helpful discussions and assistance with the Section "Materials and Methods."

\section{SUPPLEMENTARY MATERIAL}

The Supplementary Material for this article can be found online at: https://www.frontiersin.org/articles/10.3389/fpls.2018.01848/ full\#supplementary-material

Brzezowski, P., Richter, A. S., and Grimm, B. (2015). Regulation and function of tetrapyrrole biosynthesis in plants and algae. Biochim. Biophys. Acta 1847, 968-985. doi: 10.1016/j.bbabio.2015.05.007

Chae, H. Z., Chung, S. J., and Rhee, S. G. (1994). Thioredoxin-dependent peroxide reductase from yeast. J. Biol. Chem. 269, 27670-27678.

Chao, H. F., Yen, Y. F., and Ku, M. S. (2009). Characterization of a salt-induced DhAHP, a gene coding for alkyl hydroperoxide reductase, from the extremely halophilic yeast Debaryomyces hansenii. BMC Microbiol. 9:182. doi: 10.1186/ 1471-2180-9-182

Day, A. M., Brown, J. D., Taylor, S. R., Rand, J. D., Morgan, B. A., and Veal, E. A. (2012). Inactivation of a peroxiredoxin by hydrogen peroxide is critical for thioredoxin-mediated repair of oxidized proteins and cell survival. Mol. Cell. 45, 398-408. doi: 10.1016/j.molcel.2011.11.027 
Dietz, K. J. (2007). The dual function of plant peroxiredoxins in antioxidant defence and redox signaling. Subcell Biochem. 44, 267-294. doi: 10.1007/9781-4020-6051-9_13

Dietz, K. J., Horling, F., Konig, J., and Baier, M. (2002). The function of the chloroplast 2-cysteine peroxiredoxin in peroxide detoxification and its regulation. J. Exp. Bot. 53, 1321-1329.

Dietz, K. J., Jacob, S., Oelze, M. L., Laxa, M., Tognetti, V., de Miranda, S. M., et al. (2006). The function of peroxiredoxins in plant organelle redox metabolism. J. Exp. Bot. 57, 1697-1709. doi: 10.1093/jxb/erj160

Falk, S., Samson, G., Bruce, D., Huner, N. P., and Laudenbach, D. E. (1995). Functional analysis of the iron-stress induced CP 43' polypeptide of PS II in the cyanobacterium Synechococcus sp. PCC 7942. Photosynth. Res. 45, 51-60. doi: 10.1007/BF00032235

Finkemeier, I., Goodman, M., Lamkemeyer, P., Kandlbinder, A., Sweetlove, L. J., and Dietz, K. J. (2005). The mitochondrial type II peroxiredoxin F is essential for redox homeostasis and root growth of Arabidopsis thaliana under stress. J. Biol. Chem. 280, 12168-12180. doi: 10.1074/jbc.M413189200

Gentleman, R. C., Carey, V. J., Bates, D. M., Bolstad, B., Dettling, M., Dudoit, S., et al. (2004). Bioconductor: open software development for computational biology and bioinformatics. Genome Biol. 5:R80. doi: 10.1186/gb-2004-5-10r80

Golden, S. S., Brusslan, J., and Haselkorn, R. (1987). Genetic engineering of the cyanobacterial chromosome. Methods Enzymol. 153, 215-231. doi: 10.1016/ 0076-6879(87)53055-5

Gorbe, E. C., and Calatayud, A. (2012). Applications of chlorophyll fluorescence imaging technique in horticultural research. Sci. Horticult. 138, 24-35. doi: 10.1016/j.scienta.2012.02.002

Guevara-Flores, A., Martinez- González, J. J., Rendon, J. L., and Del Arenal, I. P. (2017). The architecture of thiol antioxidant systems among invertebrate parasites. Molecules 22:E259. doi: 10.3390/molecules22020259

Halimatul, H. S., Ehira, S., and Awai, K. (2014). Fatty alcohols can complement functions of heterocyst specific glycolipids in Anabaena sp. PCC 7120. Biochem. Biophys. Res. Commun. 450, 178-183. doi: 10.1016/j.bbrc.2014. 05.093

Havaux, M., Guedeney, G., He, Q., and Grossman, A. R. (2003). Elimination of high-light-inducible polypeptides related to eukaryotic chlorophyll a/b-binding proteins results in aberrant photoacclimation in Synechocystis PCC6803. Biochim. Biophys. Acta 1557, 21-33. doi: 10.1016/S0005-2728(02)00391-2

Hiei, Y., Ohta, S., Komari, T., and Kumashiro, T. (1994). Efficient transformation of rice (Oryza sativa L.) mediated by Agrobacterium and sequence analysis of the boundaries of the T-DNA. Plant J. 6, 271-282. doi: 10.1046/j.1365-313X. 1994.6020271.x

Hodges, D. M., Delong, J. M., Forney, C. F., and Prange, R. K. (1999). Improving the thiobarbituric acid-reactive-substances assay for estimating lipid peroxidation in plant tissues contating anthocyanin and other interfering compounds. Planta 207, 604-611. doi: 10.1007/s004250050524

Huang, T., Lin, J., Cao, J., Zhang, P., Bai, Y., Chen, G., et al. (2012). An exopolysaccharide from Trichoderma pseudokoningii and its apoptotic activity on human leukemia K562 cells. Carbohydr. Polym. 89, 701-708. doi: 10.1016/j. carbpol.2012.03.079

Jang, H. H., Lee, K. O., Chi, Y. H., Jung, B. G., Park, S. K., Park, J. H., et al. (2004). Two enzymes in one; two yeast peroxiredoxins display oxidative stressdependent switching from a peroxidase to a molecular chaperone function. Cell 117, 625-635. doi: 10.1016/j.cell.2004.05.002

Jing, L. W., Chen, S. H., Guo, X. L., Zhang, H., and Zhao, Y. X. (2006). Overexpression of a chloroplast-located peroxiredoxin Q gene, SsPrxQ, increases the salt and low-temperature tolerance of Arabidopsis. J. Integr. Plant Biol. 48, 1244-1249. doi: 10.1111/j.1744-7909.2006.00357.x

Kim, I. S., Kim, Y. S., and Yoon, H. S. (2013). Expression of salt-induced 2-Cys peroxiredoxin from Oryza sativa increases stress tolerance and fermentation capacity in genetically engineered yeast Saccharomyces cerevisiae. Appl. Microbiol. Biotechnol. 97, 3519-3533. doi: 10.1007/s00253-012-4410-8

Kim, K. H., Alam, I., Lee, K. W., Sharmin, S. A., Kwak, S. S., Lee, S. Y., et al. (2010). Enhanced tolerance of transgenic tall fescue plants overexpressing 2Cys peroxiredoxin against methyl viologen and heat stresses. Biotechnol. Lett. 32, 571-576. doi: 10.1007/s10529-009-0185-0

Kim, M. D., Kim, Y. H., Kwon, S. Y., Jang, B. Y., Lee, S. Y., Yun, D. J., et al. (2011). Overexpression of 2-cysteine peroxiredoxin enhances tolerance to methyl viologen-mediated oxidative stress and high temperature in potato plants. Plant Physiol. Biochem. 49, 891-897. doi: 10.1016/j.plaphy.2011.04.001

Kim, Y. S., Kim, I. S., Boyd, J. S., Taton, A., Golden, J. W., and Yoon, H. S. (2017). Enhanced biomass and oxidative stress tolerance of Synechococcus elongatus PCC 7942 overexpressing the DHAR gene from Brassica juncea. Biotechnol. Lett. 39, 1499-1507. doi: 10.1007/s10529-017-2382-6

Kim, Y. S., Kim, I. S., Choe, Y. H., Bae, M. J., Shin, S. Y., Park, S. K., et al. (2014). Overexpression of dehydroascorbate reductase confers enhanced tolerance to salt stress in rice plants (Oryza sativa L. japonica). J. Argon. Crop Sci. 200, 444-456. doi: 10.1111/jac.12078

Klughammer, B., Baier, M., and Dietz, K. J. (1998). Inactivation by gene disruption of 2-cysteine-peroxiredoxin in Synechocystis sp. PCC 6803 leads to increased stress sensitivity. Physiol. Plant. 104, 699-706. doi: 10.1034/j.1399-3054.1998. 1040426.x

Kobayashi, M., Ishizuka, T., Katayama, M., Kanehisa, M., BhattacharyyaPakrasi, M., Pakrasi, H. B., et al. (2004). Response to oxidative stress involves a novel peroxiredoxin gene in the unicellular cyanobacterium Synechocystis sp. PCC 6803. Plant Cell Physiol. 45, 290-299.

Komatsu, S., Yamamoto, R., Nanjo, Y., Mikami, Y., Yunokawa, H., and Sakata, K. (2009). A comprehensive analysis of the soybean genes and proteins expressed under flooding stress using transcriptome and proteome techniques. J. Proteome Res. 8, 4766-4778. doi: 10.1021/pr900460x

König, J., Lotte, K., Plessow, R., Brockhinke, A., Baier, M., and Dietz, K. J. (2003). Reaction mechanism of plant 2-Cys peroxiredoxin. Role of the $\mathrm{C}$ terminus and the quaternary structure. J. Biol. Chem. 278, 24409-24420. doi: 10.1074/jbc. M301145200

Kristoffersen, A. S., Hamre, B., Frette, Ø., and Erga, S. R. (2016). Chlorophyll $a$ fluorescence lifetime reveals reversible UV-induced photosynthetic activity in the green algae Tetraselmis. Eur. Biophys. J. 45, 259-268. doi: 10.1007/s00249015-1092-z

Lee, K. O., Jang, H. H., Jung, B. G., Chi, Y. H., Lee, J. Y., Choi, Y. O., et al. (2000). Rice 1Cys-peroxiredoxin over-expressed in transgenic tobacco does not maintain dormancy but enhances antioxidant activity. FEBS Lett. 486, 103-106. doi: 10.1016/S0014-5793(00)02230-4

Lee, Y. P., Kim, S. H., Bang, J. W., Lee, H. S., Kwak, S. S., and Kwon, S. Y. (2007). Enhanced tolerance to oxidative stress in transgenic tobacco plants expressing three antioxidant enzymes in chloroplasts. Plant Cell Rep. 26, 591-598. doi: 10.1007/s00299-006-0253-z

Leal, M. C., Jesus, B., Ezequiel, J., Calado, R., Rocha, R. J. M., Cartaxana, P., et al. (2015). Concurrent imaging of chlorophyll fluorescence, Chlorophyll $a$ content and green fluorescent proteins-like proteins of symbiotic cnidarians. Mar. Ecol. 36, 572-584. doi: 10.1111/maec.12164

Messina, C. M., Faggio, C., Laudicella, V. A., Sanfilippo, M., Trischitta, F., and Santulli, A. (2014). Effect of sodium dodecyl sulfate (SDS) on stress response in the Mediterranean mussel (Mytilus Galloprovincialis): regulatory volume decrease (Rvd) and modulation of biochemical markers related to oxidative stress. Aquat. Toxicol. 157, 94-100. doi: 10.1016/j.aquatox.2014. 10.001

Mittler, R., Vanderauwera, S., Gollery, M., and Van Breusegem, F. (2004). Reactive oxygen gene network of plants. Trends Plant Sci. 9, 490-498. doi: 10.1016/j. tplants.2004.08.009

Moon, J. C., Hah, Y. S., Kim, W. Y., Jung, B. G., Jang, H. H., Lee, J. R., et al. (2005). Oxidative stress-dependent structural and functional switching of a human 2-Cys peroxiredoxin isotype II that enhances HeLa cell resistance to H2O2-induced cell death. J. Biol. Chem. 280, 28775-28784. doi: 10.1074/jbc. M505362200

Nikkanen, L., and Rintamaki, E. (2014). Thioredoxin-dependent regulatory networks in chloroplasts under fluctuating light conditions. Philos. Trans. R. Soc. Lond. B Biol. Sci. 369:20130224. doi: 10.1098/rstb.2013.0224

Park, S. I., Kim, Y. S., Kim, J. J., Mok, J. E., Kim, Y. H., Park, H. M., et al. (2017). Improved stress tolerance and productivity in transgenic rice plants constitutively expressing the Oryza sativa glutathione synthetase OsGS under paddy field conditions. J. Plant Physiol. 215, 39-47. doi: 10.1016/j.jplph.2017. 05.006

Pascual, M. B., Mata-Cabana, A., Florencio, F. J., Lindahl, M., and Cejudo, F. J. (2010). Overoxidation of 2-Cys peroxiredoxin in prokaryotes: cyanobacterial 2-Cys peroxiredoxins sensitive to oxidative stress. J. Biol. Chem. 285, 3448534492. doi: 10.1074/jbc.M110.160465 
Peng, L., Kapp, E. A., McLauchlan, D., and Jordan, T. W. (2011). Characterization of the asia oceania human proteome organisation membrane proteomics initiative standard using SDS-PAGE shotgun proteomics. Proteomics 11, 43764384. doi: 10.1002/pmic.201100169

Puerto, G., Erazo, L., Wintaco, M., Castro, C., Ribon, W., and Guerrero, M. I. (2015). Mycobacterium tuberculosis genotypes determined by spoligotyping to be circulating in colombia between 1999 and 2012 and their possible associations with transmission and susceptibility to first-line drugs. PLoS One 10:e0124308. doi: 10.1371/journal.pone.012 4308

Rai, R., Pandey, S., Shrivastava, A. K., and Pandey Rai, S. (2014). Enhanced photosynthesis and carbon metabolism favor arsenic tolerance in Artemisia annua, a medicinal plant as revealed by homology-based proteomics. Int. J. Proteomics 2014:163962. doi: 10.1155/2014/163 962

Rouhier, N., and Jacquot, J. P. (2008). Getting sick may help plants overcome abiotic stress. New Phytol. 180, 738-741. doi: 10.1111/j.1469-8137.2008.02673.x

Sayed, A. A., and Williams, D. L. (2004). Biochemical characterization of 2-Cys peroxiredoxins from Schistosoma mansoni. J. Biol. Chem. 279, 26159-26166. doi: 10.1074/jbc.M401748200

Schröder, E., Littlechild, J. A., Lebedev, A. A., Errington, N., Vagin, A. A., and Isupov, M. N. (2000). Crystal structure of decameric 2-Cys peroxiredoxin from human erythrocytes at 1.7 A resolution. Structure 8, 605-615. doi: 10.1016/ S0969-2126(00)00147-7

Stork, T., Laxa, M., Dietz, M. S., and Dietz, K. J. (2009). Functional characterisation of the peroxiredoxin gene family members of Synechococcus elongatus PCC 7942. Arch. Microbiol. 191, 141-151. doi: 10.1007/s00203-0080438-7
Tognetti, V. B., Palatnik, J. F., Fillat, M. F., Melzer, M., Hajirezaei, M. R., Valle, E. M., et al. (2006). Functional replacement of ferredoxin by a cyanobacterial flavodoxin in tobacco confers broad-range stress tolerance. Plant Cell 18, 2035-2050. doi: 10.1105/tpc.106.042424

Wood, Z. A., Poole, L. B., and Karplus, P. A. (2003). Peroxiredoxin evolution and the regulation of hydrogen peroxide signaling. Science 300, 650-653. doi: 10.1126/science.1080405

Yamamoto, H., Miyake, C., Dietz, K. J., Tomizawa, K., Murata, N., and Yokota, A. (1999). Thioredoxin peroxidase in the cyanobacterium synechocystis sp. PCC 6803. FEBS Lett. 447, 269-273.

Zeng, Q., Chen, X., and Wood, A. J. (2002). Two early light-inducible protein (ELIP) cDNAs from the resurrection plant Tortula ruralis are differentially expressed in response to desiccation, rehydration, salinity, and high light. J. Exp. Bot. 53, 1197-1205. doi: 10.1093/jexbot/53.371.1197

Zheng, M., Doan, B., Schneider, T. D., and Storz, G. (1999). OxyR and SoxRS regulation of fur. J. Bacteriol. 181, 4639-4643.

Conflict of Interest Statement: The authors declare that the research was conducted in the absence of any commercial or financial relationships that could be construed as a potential conflict of interest.

Copyright (c) 2018 Kim, Kim, Park, Diamond, Boyd, Taton, Kim, Golden and Yoon. This is an open-access article distributed under the terms of the Creative Commons Attribution License (CC BY). The use, distribution or reproduction in other forums is permitted, provided the original author(s) and the copyright owner(s) are credited and that the original publication in this journal is cited, in accordance with accepted academic practice. No use, distribution or reproduction is permitted which does not comply with these terms. 